\title{
NGT
}

National Institute of

Standards and Technology

U.S. Department of Commerce

Materials Testing

Standards for Additive

Manufacturing of Polymer

Materials:

State of the Art and Standards Applicability

Aaron M. Forster

NISTIR 8059 
NISTIR 8059

\section{Materials Testing Standards for Additive Manufacturing of Polymer Materials: State of the Art and Standards Applicability}

This publication is available free of charge from: http://dx.doi.org/10.6028/NIST.IR.8059

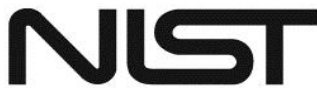

National Institute of 
NISTIR 8059

\section{Materials Testing Standards for Additive Manufacturing of Polymer Materials: State of the Art and Standards Applicability}

Aaron M. Forster

Materials and Structural Systems Division

Engineering Laboratory

This publication is available free of charge from:

http://dx.doi.org/10.6028/NIST.IR.8059

May 2015

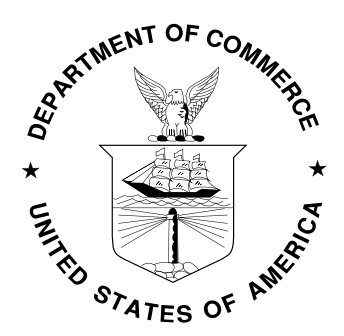

U.S. Department of Commerce

Penny Pritzker, Secretary

National Institute of Standards and Technology

Willie May, Under Secretary of Commerce for Standards and Technology and Director 


\title{
National Institute of Standards and Technology Interagency Report 8059 54 pages (May 2015)
}

\author{
This publication is available free of charge from: \\ http://dx.doi.org/10.6028/NIST.IR.8059
}

Certain commercial entities, equipment, or materials may be identified in this document in order to describe an experimental procedure or concept adequately. Such identification is not intended to imply recommendation or endorsement by NIST, nor is it intended to imply that the entities, materials, or equipment are necessarily the best available for the purpose.

There may be references in this publication to other publications currently under development by NIST in accordance with its assigned statutory responsibilities. The information in this publication, including concepts and methodologies, may be used by Federal agencies even before the completion of such companion publications. Thus, until each publication is completed, current requirements, guidelines, and procedures, where they exist, remain operative. For planning and transition purposes, Federal agencies may wish to closely follow the development of these new publications by NIST.

Organizations are encouraged to review all draft publications during public comment periods and provide feedback to NIST. All NIST Computer Security Division publications, other than the ones noted above, are available at http://csrc.nist.gov/publications.

\section{Comments on this publication may be sent to:}

\author{
National Institute of Standards and Technology \\ Attn: Computer Security Division, Information Technology Laboratory \\ 100 Bureau Drive (Mail Stop 8930) Gaithersburg, MD 20899-8930
}




\begin{abstract}
Additive manufacturing (AM) continues to grow as an advanced manufacturing technique. The most recent industry report from Wohlers and Associates indicates AM represented \$1.6B in revenue from parts, systems, and other supporting industries in 2012 and is expected to grow to more than $\$ 3.5 \mathrm{~B}$ by 2017 and to $\$ 10 \mathrm{~B}$ by 2022 . The measurement challenges for AM, whether the deposited material is metal or polymer, are similar. Parallels between the additive manufacturing for metals and polymers include: characterization of raw materials, development of material properties for design, in-situ process and feedback control, workflow optimization, and modeling final properties. The scope of this report is to analyze the current trends in polymer additive manufacturing and determine the applicability of current American Society for Testing Materials International (ASTM) and the International Standards Organization (ISO) standard test methods for mechanical properties and failure of polymers and polymer composites generated from the additive manufacturing processes. The current approach to mechanical testing standards utilizes existing guidelines for testing materials, but this analysis highlights the need to develop specific guidelines for testing AM materials. The current AM efforts at NIST towards polymers are supported through the Material Measurement Laboratory (MML) AM program. While this program is addressing critical measurement science to validate polymer physics within AM, it is not directly translating this knowledge into the standards required for engineering design. The emerging engineering and standards challenges for high performance polymers and polymer composites are not currently addressed by the Engineering Laboratory (EL) Additive Manufacturing program, which is focused on metal applications. The development of a program to bridge the measurement gap between molecular architecture of AM materials (MML) and generating engineering properties for design represents an opportunity for the EL effort.
\end{abstract}

Key words: additive manufacturing, polymer, mechanical properties, standards, testing 


\section{Table of Contents}

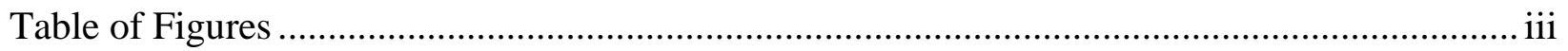

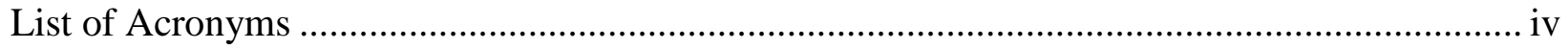

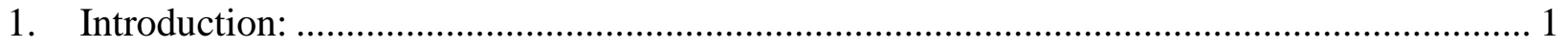

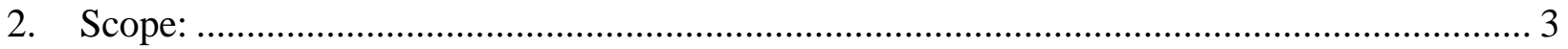

3. Government and Academic Support: ..................................................................... 4

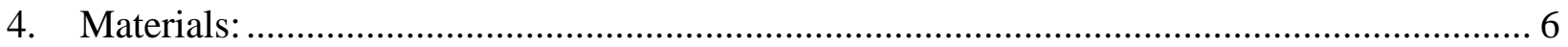

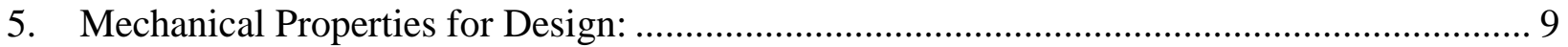

6. Challenges for Mechanical Property Characterization:..................................................... 15

7. Overview of Standard Testing Methods ........................................................................ 19

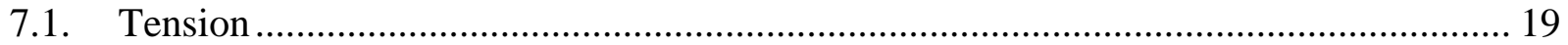

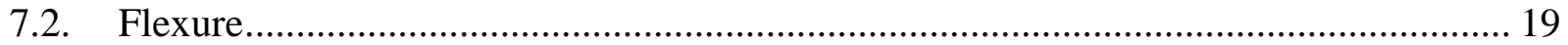

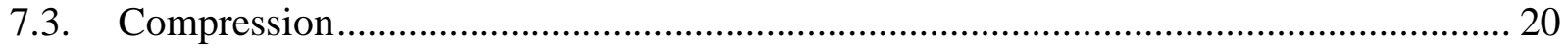

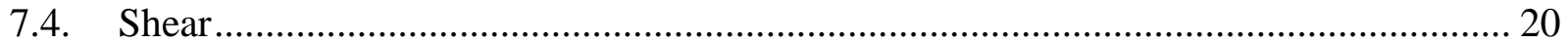

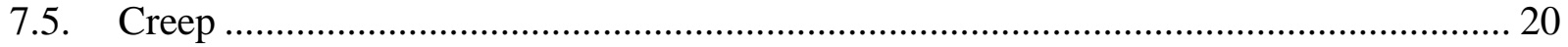

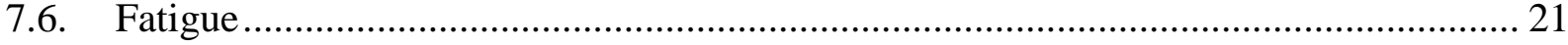

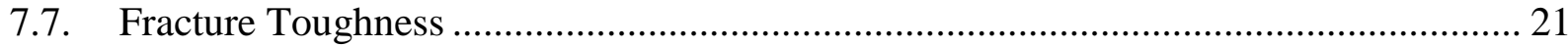

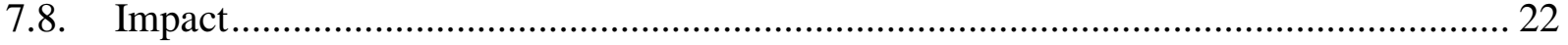

7.9. Bearing Strength and Open Hole Compression ....................................................... 23

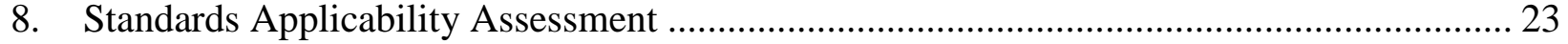

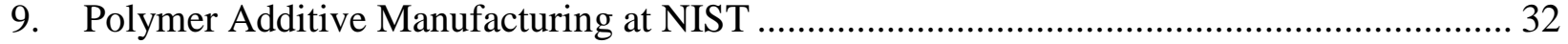

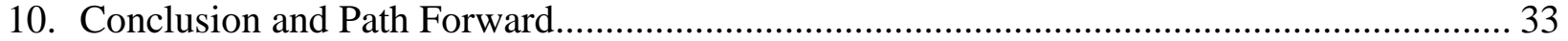

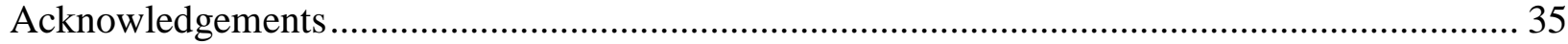

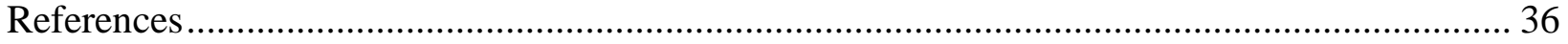




\section{Table of Figures}

Figure 1: Pie chart showing the types of material utilized for AM as fraction of material

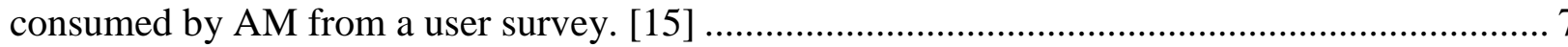

Figure 2: Building block integration for the development of composite structures [53]............ 10

Figure 3: Building block approach for the support of composites structures in the 777 aircraft [53]. In this graphic durability is defined through moisture stability, temperature stability, creep resistance, and fatigue resistance.

Figure 4: Mesostructure of an ME-ABS material illustrating the porous structure that may be achieved based on the raster angle and bead overlap [54]

Figure 5: Graphic illustrating the directionality of fibers, through $\mathrm{z}$, in a fiber composite laminate. The orientation and number of fibers controls the performance of the composite

Figure 6: Three modes of crack surface displacements Mode I (opening or tensile mode), Mode II (sliding mode), and Mode III (tearing mode) copied from [56].

Figure 7: Graphical representation of process variables related to the build geometry for additive manufacturing. a) raster angle, b) extruded filament height and layer width, c) air gap between extruded filaments, d) combinations of variables ( $T$, air gap, width, height, velocity) can increase the coalescence between filaments, e) the build direction can affect the load transfer between filaments and interfaces. 


\section{List of Acronyms}

AMC, Additive Manufacturing Consortium - A national consortium of industry, government, academic, and non-profit research organizations with the mission of accelerating and advancing the manufacturing readiness of metal additive manufacturing technology.

AM, additive manufacturing - a process of joining materials to make objects from 3D model data, usually layer upon layer, as opposed to subtractive manufacturing methodologies [1].

AmericaMakes - is the National Additive Manufacturing Innovation Institute. AmericaMakes is focused on helping the United States grow capabilities and strength in 3D printing. It is based in Youngstown, Ohio and is an extensive network of more than 100 companies, non-profit organizations, academic institutions and government agencies [2].

ARL - Army Research Laboratory.

ASTM - American Society of Testing Materials International.

Battelle - Battelle Memorial Institute is the world's largest nonprofit research and development organization.

CAD/CAM - Computer Aided Design/Computer Aided Machining.

CAMM, Consortium for Additive Manufacturing Materials - The organizational component of CIMP 3D. It was created from a NIST Advanced Manufacturing Technology Consortia (AMTech) Program grant to foster innovation in additive manufacturing.

CIMP 3D, Center for Innovative Materials Processing Through Direct Digital Deposition A consortium administered by Pennsylvania State University, Batelle, and Sciaky Corporation. It is a resource for AM technology for critical applications [3].

CNC, computer numerical control - indicative of computer-controlled machinery for cutting various hard materials. These are synonymous with subtractive manufacturing methods.

DARPA - Defense Advanced Research Projects Agency.

FDM - a material extrusion process used to make thermoplastic parts through heated extrusion and deposition of materials layer by layer; term denotes machines built by Stratasys, Inc [1].

ISO - International Standards Organization.

LS, laser sintering - a powder bed fusion process used to produce objects from powdered materials using one or more layers to selectively fuse or melt the particles at the surface, layer by layer, in an enclosed chamber [1]. 
NAMII, National Additive Manufacturing Innovation Institute - The pilot institute from NNMI established in 2012. This consortium includes 40 companies, nine research universities, five community colleges, and 11 nonprofit organizations. This consortium is also called AmericaMakes [4].

NCDMM, National Center for Defense Manufacturing and Machining - the driver of AmericaMakes. The mission is to deliver optimized manufacturing solutions that enhance the quality, affordability, maintainability, and rapid deployment of existing and yet-to-be developed defense systems [5].

NNMI, National Network for Manufacturing Innovation - A federally backed network established by the Revitalize American Manufacturing Act. The institutes developed under NNMI are intended to create a competitive, effective, and sustainable manufacturing research-tomanufacturing infrastructure for U.S. industry and academia to solve industry-relevant problems. ME, material extrusion - an additive manufacturing process in which a material is selectively dispensed through a nozzle or orifice [1].

MSAM, Measurement Science for Advanced Manufacturing - A cooperative agreement program that solicits proposals for grants to advanced manufacturing. The program is administered by the National Institutes of Standards and Technology. This is the program developed to administer grants for the NNMI.

ONR - Office of Naval Research

ORNL - Oak Ridge National Laboratory 


\section{Introduction':}

Additive manufacturing is a process of joining materials to make objects from 3D model data, usually in a layer by layer process $[1,6]$. The objects are created in CAD/CAM software, transformed to machining instructions similar to the process for $\mathrm{CNC}$ machining, and each layer is directly fabricated on top of previous layers to create a replica of the object. In general, this manufacturing process is not subtractive. Multiple processes exist to create polymeric materials and composites, but they generally fall into three classes: material extrusion, powder bed fusion, and material jetting.

Material Extrusion (ME) is a process that selectively dispenses a thermoplastic polymer through a nozzle. Stratasys has trademarked the term fused deposition modeling (FDM $®$ ) to identify their systems that utilize this technique [1]. The extrusion head melts the plastic filament, extrudes material through a nozzle, and places the resin bead onto the substrate. This is a less aggressive process compared to injection molding where the plastic is melted and uniformly blended using a screw extruder to inject the material at high pressure into a mold. There are specific challenges for additive manufacturing that are unique to polymeric materials. In ME, heat is used to melt a polymer filament and the material is directed to a specific location via a nozzle. This places a polymer beads or filament of a specific size and length onto the substrate. Successive beads are layered to create the final 3D structure. The strength of the part is generated from the deposited material properties and the interface between beads. The interface is important because the neighboring beads are at a lower temperature than the molten bead leaving the nozzle. The thermal gradient between the two materials will melt the existing bead and cause polymers molecule to diffuse across the interface. The strength of this fusion is dependent on many factors such as temperature gradient, polymer structure (molecular weight, branching, heat of fusion, glass transition temperature, etc.), and bead geometry. It is possible for this fusion to exist under stress prior to any mechanical loading. As the beads cool, the polymer contracts which creates a localized residual stress. As the performance of AM materials is increased by using semicrystalline and more rigid polymers, the physics to model interfacial strength and stress are different than amorphous materials. There are additional challenges such as ME surface roughness, void space between beads, and defects (excess material) that can initiate failure modes within the part under loading. The nature of the printing process and the aligned structure of the beads make AM parts highly anisotropic and this anisotropy may exhibit a non-linear dependence on processing parameters.

Laser sintering (LS), or powder bed fusion, is a process that utilizes directed energy to melt a thermoplastic powder similar to the process used to generate parts from metal powders. This process starts with a powder bed of polymer powder of a specific layer height and temperature. A high powered laser is rastered across the surface to locally heat the polymer pellets. At this

\footnotetext{
${ }^{1}$ Certain commercial equipment, instruments, or materials are identified in this paper to foster understanding. Such identification does not imply recommendation or endorsement by the National Institute of Standards and Technology, nor does it imply that the materials or equipment identified are necessarily the best available for the purpose.
} 
point, two thermal processes could occur depending on the machine design. The laser could fully melt the polymer pellets and allow the molten material to flow and diffuse into adjacent material. The second process locally heats the pellets to allow diffusion of polymer between adjacent pellets and layers. This is equivalent to a sintering process. In either case, the locally heated polymer diffuses to create a single layer within the part. A fresh layer of powder material is placed on top of the previous layer and the laser again melts local regions of polymer. The strength of parts is dependent on the ability of the process to manage thermal gradients. The molten material must flow into cracks adjacent to previous layers and the thermal gradient must be high enough to allow entanglement between neighboring polymer layers [7]. These parts tend to exhibit anisotropy characteristic of the laser scanning direction or build (Z) direction and can exhibit location dependent voids.

The material jetting process, which is similar to early stereolithography methods used for rapid prototyping [8], utilizes an inkjet print head to deposit a thin layer of photopolymerizable polymer and initiator. Ultraviolet lamps, or similar energy source, at the print head initiate cure of the photopolymer layer as it is deposited [9]. Direct printing processes have challenges related to the chemistry of the photocurable polymers used to build parts. Localized curing may be inhomogeneous which leads to a range of mechanical properties throughout the part. Uncrosslinked material trapped within holes may plasticize or age the part causing premature failure [10].

Additive manufacturing (AM) continues to grow as an advanced manufacturing technique. The most recent industry report from Wohlers and Associates indicates AM represented \$1.6B in revenue from parts, systems, and other supporting industries in 2012 [11] and is expected to grow to more than $\$ 3.5 \mathrm{~B}$ by 2017 [12] and to $\$ 10 \mathrm{~B}$ by 2022 [13]. The AM material market is expected to grow from $\$ 470 \mathrm{M}$ in 2013 to over $\$ 1.09 \mathrm{~B}$ in 2022 [13]. Industry, government and academia in the U.S. have been working to support the rate of growth by expanding machine capabilities and developing new high strength and biomedical materials. A report by IDTechEx as reported in The Guardian indicates the dental and medical market is expected to expand to $\$ 867 \mathrm{M}$ by 2025 , the inclusion of additively manufactured organs and tissues would mean a potential of $\$ 6 \mathrm{~B}$ within 10 years $[14,15]$.

Currently, there are few standards specifically addressing mechanical properties of AM parts. ASTM F42.01 has a number of standards and work items focused on metals AM [16]. There is currently one ASTM standard test method applicable to powder bed fusion of plastic materials; F3091/F3019M-14 Standard Specification for Powder Bed Fusion of Plastic Materials [17]. The subcommittee has one work item that covers evaluation of manufacturing systems: WK 40419 New Test Methods for Performance evaluation of additive manufacturing systems through measurement of a manufactured test piece [18]. The International Standards Organization (ISO) has one active standard: ISO 17296-3:2014 Additive Manufacturing - General Principles-Part 3: Main characteristics and corresponding test methods [19] to address quality characteristics of parts produced by AM. This standard references other ISO standards for mechanical property testing of polymers and metals, but there are no AM specific considerations in testing. The lack of AM specific mechanical standards creates challenges for stakeholders to provide equal comparisons between machines, materials, and models that predict final part properties in order 
to generate design allowables. Stahl has identified the inferior mechanical performance compared to that for traditionally manufactured parts as a risk for AM [20].

\section{Scope:}

The measurement challenges for AM, whether it is metal or polymer, are similar. Parallels between the material systems include: characterization of raw materials, development of design allowables, in-situ process and feedback control, workflow optimization, and modeling final properties [21]. The emerging engineering and standards challenges for high performance polymers and polymer composites are not directly addressed by the Engineering Laboratory Additive Manufacturing program, which is focused on metal applications. The scope of this report is to analyze the current trends in polymer additive manufacturing and determine the applicability of current ASTM and the ISO standard test methods for mechanical properties and failure of polymers and polymer composites generated from the additive manufacturing processes.

This report follows the style of previous NIST Internal Reports (NISTIR), NISTIR 8005 [22] and NISTIR 7847 [23], from EL to document the standards needs in metal AM. This report will provide:

a. State of the art for additive manufacturing of polymers and polymer composites

b. Analysis of the technical hurdles that are preventing these materials from high performance manufacturing applications.

c. Analysis of the current ASTM and ISO standards for measuring mechanical properties and failure of polymers and composites to include:

i. Standard designation,

ii. Standard Name,

iii. Application to AM testing,

iv. Notes concerning each standard relevant to the AM,

d. Summary of recommended potential directions for NIST standards research in polymer additive manufacturing.

This report will also describe the emerging effort in the Material Measurement Laboratory (MML) to support polymer additive manufacturing efforts and the potential opportunities for leveraging collaborative efforts between MML and the Engineering Laboratory. In order to limit the scope of this effort, concessions were made to focus on materials, measurement length scales, and types of standards as described below:

- $\underline{\text { Polymers }}-$ Standardized methods for measuring the mechanical properties polymeric materials utilized in ME, laser sintering, and direct printing were addressed. Mechanical property measurement standards for polymer matrix fiber reinforced composites were also included for review. Fiber reinforced composites use a polymer matrix to support woven or aligned high strength fibers. Manufacturing composites requires stacking multiple layers of fibers and infusing the interstitial spacing with a polymer resin. The fibers are strong in the axial direction 
and weaker in the radial direction; the fibers provide anisotropy to the strength of the composite. Therefore, standardized measurements developed for mechanical properties in fiber reinforced composites may be applicable to additively manufactured materials.

- Bulk Mechanical Properties - Standardized methods for bulk property measurements were addressed. Mechanical property measurements of localized properties, like those obtained by micro-indentation, hardness, and atomic force microscopy were excluded.

- Focus on International Standards - This was done in order to make the assessment practical. A cursory review of standards from the major Standards Development Organizations showed that ASTM and ISO mechanical testing standards are representative of all the pertinent standardized mechanical testing methods. A number of industry groups have developed protocols for reference tests. These tests are useful and some eventually become standards. Such tests are not covered here for three reasons: there are many such tests, often they are specific to an industry sector or product, and many are consensus methods that may lack the rigorous scientific basis and round-robin verification that is required for a standard.

\section{Government and Academic Support:}

In 2009 the National Science Foundation (NSF) developed a Roadmap for Additive Manufacturing [24]. This roadmap addressed various challenges faced by the industry in the areas of design, materials, biomaterials, and energy and sustainability. The main recommendations from this roadmap were to:

- expand the capabilities of solid modeling to support additive manufacturing,

- develop better closed loop and feedback control,

- develop predictive process-structure-property relationships integrated into CAD/CAM tools,

- improve physical models of AM processes to maximize the properties of AM parts, develop and adopt internationally recognized standards which are useful to product, process, and material certification

Chapter 6 of this report highlights the types of material properties that are measured to determine the engineering properties used to design structures. In addition, understanding the anisotropy of AM parts allows specific functionality to be built into the manufacturing process and this allows unique capabilities not achievable through other manufacturing methods. NSF funded additive manufacturing to a total of \$200M from 1986 to 2012 [24].

In 2012 the creation of the National Network for Manufacturing Innovation (NNMI) was started by the Executive Office of the President to develop regional advanced manufacturing hubs [4]. One of the first hubs was AmericaMakes. AmericaMakes is a partnership among the Departments of Commerce, Defense, Energy, NASA, and NSF. This effort led to the funding of the National Center for Defense Manufacturing and Machining (NCDMM) in Youngstown Ohio, which brings together a regional network of 14 research universities, community colleges, 40 industry partners, and 10 non-profit organizations spanning Western Pennsylvania, Eastern Ohio, and West Virginia. This effort is funded with a $\$ 40 \mathrm{M}$ private match to the initial $\$ 30 \mathrm{M}$ federal 
investment. NIST's Measurement Science for Advanced Manufacturing program (MSAM) has funded NCDMM with \$5M for research to ensure quality parts are produced from LS of metal powders [25]. The NCDMM mission is to build a national network for additive manufacturing and $3 \mathrm{D}$ printing technologies in the U.S. [5].

Currently, AmericaMakes is funding projects for ME processing of high-temperature commercial polymers, ME for complex shape composite tooling, and AM manufactured composite tooling for hydroforming. The University of Texas at El Paso has formed the W.M. Keck Center for 3D Evaluation which has one project to develop integrated technologies for multi-material structures [4]. In addition, materials characterization, quality control, data sets for process-property validation, and tailored materials have been identified as critical topic areas in both project calls from AmericaMakes.

Additive manufacturing has led to several centers of development within academia. The first freeform manufacturing center was started in 1988 at The University of Texas at Austin. Pennsylvania State University started the Center for Innovative Materials Processing through Direct Digital Deposition (CIMP-3D) for metallic AM with the following government partners: DARPA, ONR, and Battelle. This consortium is developing an advanced process modeling and analysis framework for metal manufacturing. This framework includes incorporation of material science principles (microstructure, kinetics, and thermodynamics) to predict and control the final properties of the additive manufactured part. The Consortium for Additive Manufacturing Materials (CAMM) was started in 2013 as part of the NIST AMTech program $(\$ 500 \mathrm{~K})$ and will develop a comprehensive roadmapping effort for new types of additive materials [26]. The American Lightweight Materials Innovation Institute is a partnership between the Edison Welding Institute, The Ohio State University, and the University of Michigan. The University of Connecticut has recently opened the Pratt \& Whitney Additive Manufacturing Innovation Center to focus on metals. The Michigan Technological University hosts the Open Sustainability Technology Laboratory. This laboratory supports the development of open source software and hardware for all forms of additive manufacturing. The goal is to make additive manufacturing technology fully accessible to any user. North Carolina State University hosts the Center for Additive Manufacturing and Logistics. Northern Illinois University was awarded \$2.4M through the NIST MSAM program to develop physics-based AM models for process control and quality assurance [25]. Many of the academic efforts focus on the development of new materials, improvement of existing materials, development of instrumentation and test methods, and process material-property relationships for aerospace and biomedical applications. There is overlap within projects, but they are directed at improving the AM process and final products.

Additive manufacturing has recently been demonstrated for more than small parts and devices. Oak Ridge National Laboratory has partnered with Cincinnati Incorporated to develop a largescale polymer additive manufacturing system, with a goal of increasing speed by 500 times and building components that are 10 times larger $\left(>1 \mathrm{~m}^{3}\right)$ than typical AM parts $[27,28]$. Local Motors is a company that specializes in the development of large area additive manufacturing machines. This company additively manufactured an automobile during the International Manufacturing Technology Show within the exhibition hall [29]. They have recently opened an office in the National Harbor area of Washington D.C.; the large scale printer and polymers used for this demonstration were developed through collaborative research supported with ORNL. 
Andrey Rudenko additively manufactured a 2-story concrete home in the shape of a castle out of concrete [30]. While these applications remain a technical curiosity, they represent the desire to push the industry to stronger materials and applications critical to life safety.

One of the advantages of additive manufacturing is the accessibility of the technology to individuals, especially for soft materials. A large community of do-it-yourself consumers has grown up to provide open source plans for building machines, control software, start new small manufacturing businesses, and release of downloadable CAD drawings. The ease of technology transfer has spurned innovations in manufacturing at all levels. The growth of sub- $\$ 5 \mathrm{~K}$ consumer-level printers is expected to increase [31]. Further information on advances in the open source additive manufacturing market may be found at RepRap project [32] and Makerspace [33] websites.

The significant investment in AM from public-private partnerships, entrepreneurs, and the general public is expected to lead to new manufacturing technologies, better materials, and new markets for AM. Engineers require science-based standards to support design and validate mechanical performance. Machine manufacturers require methods to predict performance based on processing parameters (e.g. extrusion temperature, extrusion nozzle shape, extrusion velocity, etc.), which requires incorporation of polymer physics, constitutive equations, and improved process control methodologies. Standards will be critical to supporting competitiveness as these efforts mature to widely available manufactured products.

\section{Materials:}

Polymers are critical for AM because they represent the greatest market penetration and user accessibility [31][32][33]. The importance of polymers to materials in this community has been documented through a survey of "commons based peer production" of users available through the web [34], where polymers represent the major source of printable materials. This was a survey conducted within the open source community, mentioned earlier, to gauge their materials and manufacturing needs. Figure 1 shows the breakdown of materials used in AM printing by tonnage used in 2013. Photopolymers generated over \$239M in market revenue and the market is expected to reach $\$ 470 \mathrm{M}$ in 2022 [13]. Laser sintering equipment is not yet easily obtained by most non-manufacturing consumers because of the cost of the equipment and the difficulties in handling dispersible metal powders. Although polymers lag metals in the development of structural mechanical properties, the potential to impact many more markets from consumer products, sustainable applications, advanced manufacturing, and biomedical devices is far greater for polymers [15]. 


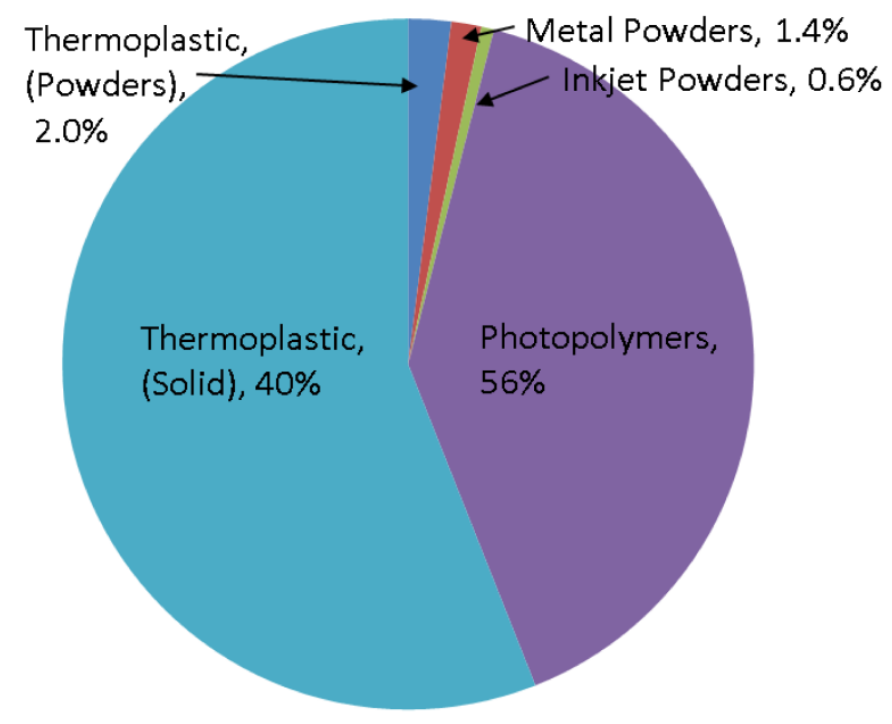

Figure 1: Pie chart showing the types of material utilized for AM as fraction of material consumed by AM from a user survey. [15]

There are a number of polymeric materials available from machine manufacturers and choices are dependent on the methodology used to create objects. A survey of websites from major equipment manufacturers, Statasys [35], 3D Systems [36], and Makerbot [37], reveal material choices that include acrylonitrile-styrene-butadiene (ABS), polycarbonate (PC), polylactide (PLA), toughened polystyrene, nylon, toughened polycarbonate, and polyurethane. Many of these materials are toughened to improve impact and fracture performance, but it is not clear whether AM takes full advantage of these properties. These materials are mainly employed for prototyping designs and the creation of low performance parts, but the demand for new higher performance polymer materials and composites is growing.

There are several examples of advances in materials, machines, and control strategies to support these advances. Equipment manufacturers offer materials that perform at high temperatures, and are chemically resistant such as polyphenylene sulfide (PPS), polyetherimide (PEI), polyphenylsulfone (PPSU), and polyether ether ketone (PEEK). There are composites systems based on glass fibers, carbon fibers, and dispersed nanomaterials [38]. The car produced via material extrusion at the International Manufacturing Technology show utilized a discontinuous carbon fiber composite developed at ORNL through the DOE Manufacturing Demonstration Facility [39]. There are additional technologies to print both discontinuous and continuous carbon fiber composites [39, 40]. Arevo Labs has announced, through a press release, the capability to print multiple high performance polymers using a combination of Solvay polymers paired to advanced instrumentation control, with a claim to deliver parts designed to achieve predicted performance [41, 42]. The Army Research Laboratory (ARL) has demonstrated the capability to produce multi-functional composites using an electric Field-Aided Laminar Composite (FALCom) processing technique [43]. This process utilizes electric fields to align nano- and micro- particles into chain-like structures that are cured into place in the photopolymer. This increases strength and provides conductive pathways for multifunctional performance. Finally, a survey of recent meeting abstracts and industry press releases show the 
industry is moving towards printing multiple materials, colors, and functionality within the same part. This will increase the complexity in predicting the final properties of the object or system.

While the choices for materials and manufacturing processes continue to improve, the ability of stakeholders to compare materials/machines for development of part design and performance has not followed a parallel path. Performance property information within the technical data sheets for these materials is not standardized. There are no defined standards to classify materials or standardized processing/manufacturing parameters used to specify the properties of a final part. A search of the technical data sheets for materials used in additive manufacturing that includes fused deposition and direct printing materials provides an idea of the important mechanical properties and the standard tests used to specify those properties. The standards are ASTM D638 (tensile strength, elongation at break, modulus of elasticity) [44], ASTM D790 (flexural strength, flexural modulus) [45], ASTM D256 (Izod Notched Impact) [46], and various hardness scales. According to ASTM D5592 [47], several of the above-referenced ASTM standards are applicable to the development of engineering design properties for load-bearing plastic components. These include ASTM D638 (tensile), ASTM D695 (compression) [48], ASTM D2990 (creep) [49], ASTM D3418 (transition temperatures for semi-crystalline polymers) [50], ASTM D4473 (dynamic mechanical for cure behavior) [51], D5045 (plane-strain fracture toughness) [52], ASTM D5279 (dynamic mechanical properties in torsion). ASTM D5592 [47] was used to identify the ASTM standards typically used in engineering design of plastics for this survey.

While manufacturers provide some traceability to mechanical property testing, the information is not complete. For example, some manufacturers provide printing parameters and others provide no printing parameters. The quality assurance provided on the raw materials prior to printing is not defined and polymers remain a black box. Manufacturers control their interactions with suppliers and the resins are tailored for their machines. Variability within molecular weight and distribution, dispersed phase volume concentration, viscosity, void content, crystallinity, range of additives and other performance qualities required for a specification are not reported. These materials are still fabricated for existing, conventional manufacturing processes such as compression or injection molding. The range of melt parameters, e.g. melt viscosity or melt index, for a commercial extrusion/injection process may not be compatible for the AM process and the lack of standardization has led to material disclaimers provided on technical datasheets, for example:

"The performance characteristics of these materials may vary according to application, operating conditions, or end use. Each user is responsible for determining that the Stratasys material is safe, lawful, and technically suitable for the intended application, as well as for identifying the proper disposal (or recycling) method consistent with applicable environmental laws and regulations. Stratasys makes no warranties of any kind, express or implied, including, but not limited to, the warranties of merchantability, fitness for a particular use, or warranty against patent infringement. The information presented in this document are typical values intended for reference and comparison purposes only. They should not be used for design specifications or quality control purposes. End-use material performance can be impacted(+/-) 
by, but not limited to, part design, end-use conditions, test conditions, color, etc. Actual values will vary with build conditions. Tested parts were built on Fortus 400 mc@0.010” (0.254 mm) slice. Product specifications are subject to change without notice."[35]

As will be demonstrated in the specific standards discussion below, process variables and manufacturing design can lead to final parts with anisotropic, inconsistent or substandard performance.

\section{Mechanical Properties for Design:}

Accurate mechanical property measurements are required to select materials and design a structure for its intended application. Engineers utilize this knowledge to make material decisions in both safety-critical and non-safety critical designs. These properties are determined using accepted measurement standards, certified databases, or reference materials. Applicable test standards are determined based on the final usage of the material, inherent weakness in the design, durability requirements, and safety factors. The Department of Defense Composite Materials Handbook has a useful reference that illustrates the staged process of a "building block approach" for determining the properties of the material and transitioning that information to the performance of the system [53]. Figure 2 shows the building block approach utilized to minimize the risk of new material insertion into aerospace structural systems. The building blocks to safely incorporate new materials into structural design rely on increasing the scale of testing from coupon tests to more complex component tests and finally full scale tests. This approach will be used to illustrate where standards for mechanical property measurements of AM manufactured parts are needed to incorporate new materials or designs into systems.

The parameters that define the system are collected within the design considerations (lower block, purple in figure). Engineers require estimates of the loading, temperature, moisture environment of the application, and material information such as mechanical properties, long term stability, susceptibility to damage, and manufacturing cost prior to designing a part. Design considerations for AM follow the same requirements as any other manufacturing process. Supporting technologies (left block, yellow in figure) are the technologies to obtain, measure, and validate the material information. In AM, this can be difficult because material property information is often controlled by manufacturers and dependent on AM processing. The engineer must decide how material properties will be validated through standard test methods, how statistical analysis will be done to determine the properties of the population, estimate the needs for post-processing of the part, and determine whether non-destructive techniques are required to validate internal structural dimensions. If these properties are dependent on material source and machine manufacturer such as in AM, it becomes difficult to estimate the level of Supporting Technologies required. The Building Blocks bring all of these considerations together (center block, green in figure). The building blocks allow engineers to understand material performance, joining or bonding performance, performance of components working together, and finally full incorporation into a full scale system test. In AM this may require significant effort for coupon level tests such as printing a single bead of material to optimize extrusion parameters, moving to ASTM dog bone geometries to identify optimal print layouts and finally incorporating the AM part into the other elements and components for further testing. In today's modeling intensive 
world, many of these concepts are validated via simulation. Therefore, science-based standardized testing is required for AM materials to support accurate simulations. This testing requires confidence in material mechanical properties and performance, which is an area that $\mathrm{AM}$ is lacking.

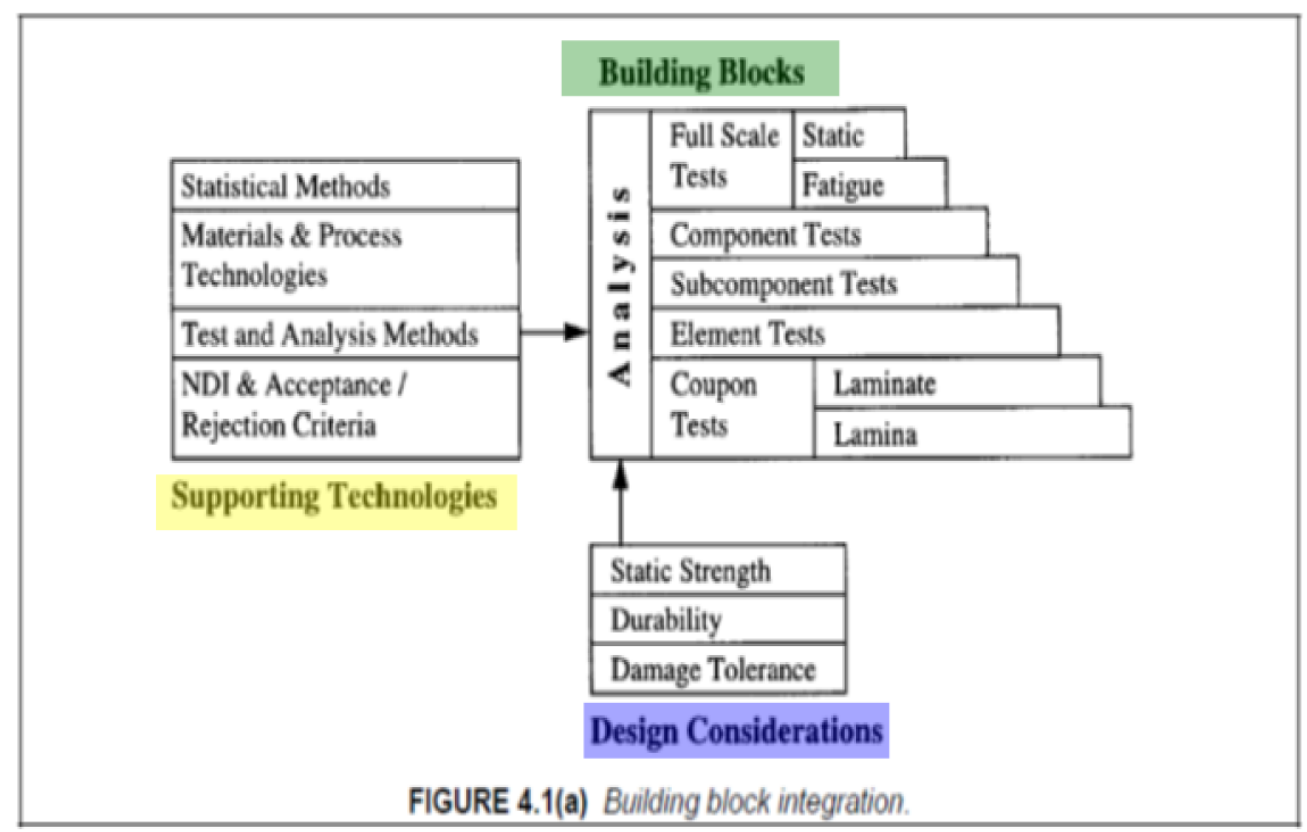

Figure 2: Building block integration for the development of composite structures [53].

The building block integration approach (Figure 2) may be further expanded to highlight the type of information gathered from each of the building blocks. Figure 3 shows the building block approach for a commercial aircraft composite primary structure to provide an estimate of the level of experimental effort anticipated at each stage of the building block. The use of aggressive environments (Environment) allows engineers to scale allowed loading or strain limits for the material based on the effects of temperature, moisture, or cycling. Coupon level testing relies on simplified sample and test geometries that deliver specific information such as mechanical properties (modulus, strength, etc.), interlaminar properties, adhesive properties, and durability (highlighted Coupons and Elements). These tests may easily number in the thousands to build statistical confidence in performance. Success beyond the coupon level leads to manufacturing smaller structures with increasing complexity for assembly (inclusion of joints and bolts) and loading (stress concentrations, off-axis loading). The costs per subcomponent increase, therefore, sampling is smaller. The coupon level and element level require a firm understanding of the impact of manufacturing processes on performance, and demand a science-based standardized testing framework to increase success in the final subcomponent stage. For any processes, weaknesses must be identified at this time to prevent costly engineering choices in the final structure and before manufacture and testing of large panels or subcomponents. An additive part will readily cross between the coupon and element level because performance may be defined by internal fusion joints, print directions, manufacturer, additive method, and material supplier. Large panels permit the validation of the design concepts and analysis methods are 
fully validated. Failure or success of the structure can validate the material design values developed from earlier testing. Each level of testing is used to support structure performance models to reduce test costs, but models rely on accurate material and interface property measurements. Accurate material and interface property measurements rely on a solid framework.

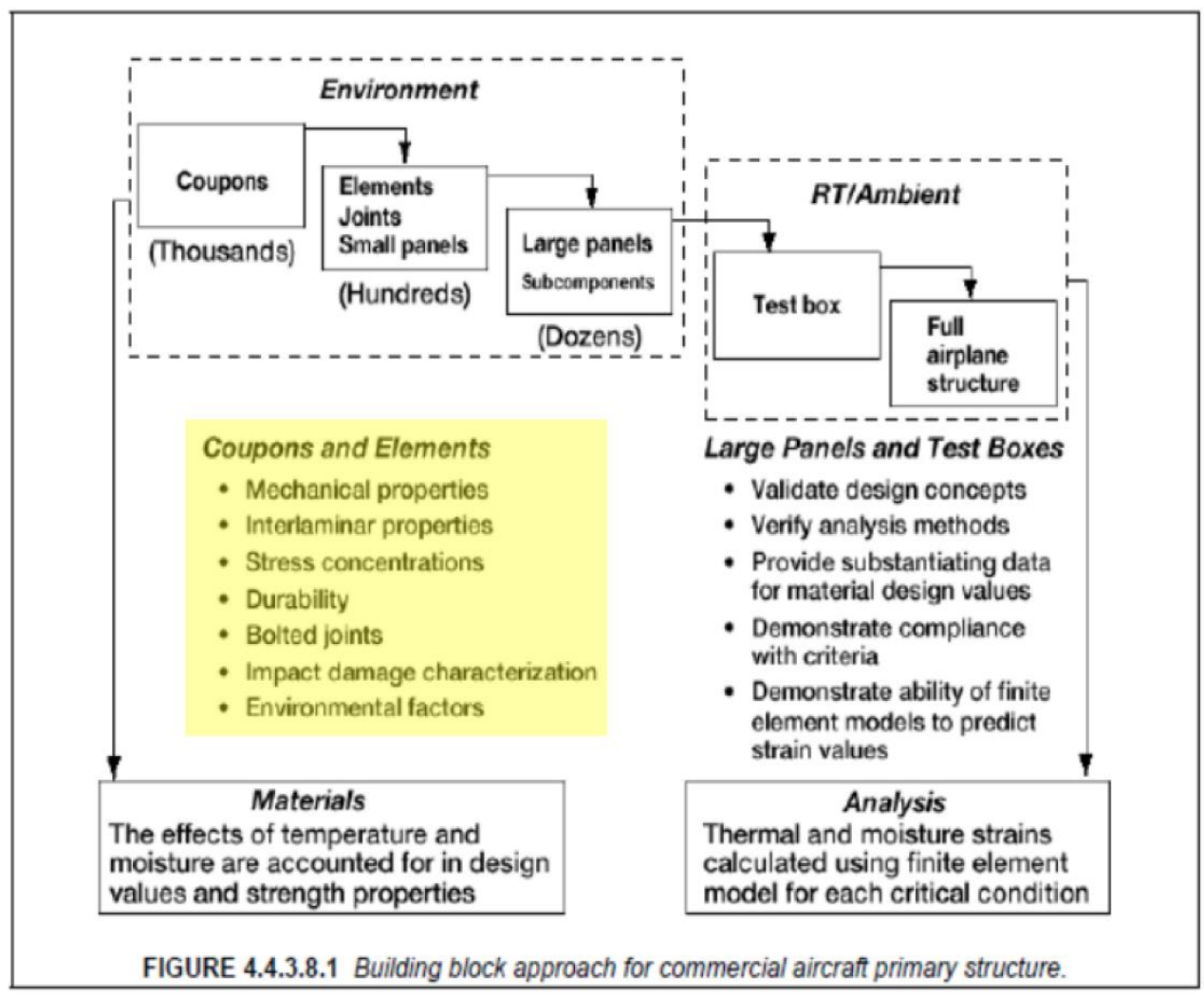

Figure 3: Building block approach for the support of composites structures in the 777 aircraft [53]. In this graphic durability is defined through moisture stability, temperature stability, creep resistance, and fatigue resistance.

From the stratified view of the building block manufacturing or qualification approach, there are identifiable challenges for AM. The first challenge is the identification of test methods for characterizing the mesostructure of the AM part at both the structural level and the molecular level. The mesostructure is defined at the structural level by anisotropy in the axial direction of extruded material, the presence of voids, and the degree of curing between reacted or melted layers during the deposition process. Many AM systems allow for complete infill (no voids) for ME and voids may not be as prolific in sintering, this does not eliminate anisotropy in mechanical performance. The mesostructure at the molecular level is defined by the degree of mixing between polymers with differing thermal histories, degrees of dispersion in composites, the coefficient of thermal expansion mismatches, and the adhesion between dissimilar materials. Both length scales lead to anisotropy in performance. Figure 4 is a cross-section of an ME produced part that highlights the potential mesostructure present from incomplete bonding between lines of extruded material. The majority of literature concerning material extrusion processes addresses the impact of different void space between lines of extruded material, 
orientation of beads to load direction, and the influence of build direction. The current focus for this overview will be the combination of material direction and void space that leads to the structural level mesostructure. These types of porous structures represent a significant challenge for engineers to determine safe design parameters. Engineers need to understand the strength of the fusion, strength of the bead, and the micromechanics of a porous structure. Standards provide the framework of scientifically grounded test geometries and methodologies to address the challenges of AM and facilitate a smooth transition between boxes to produce design parameters.

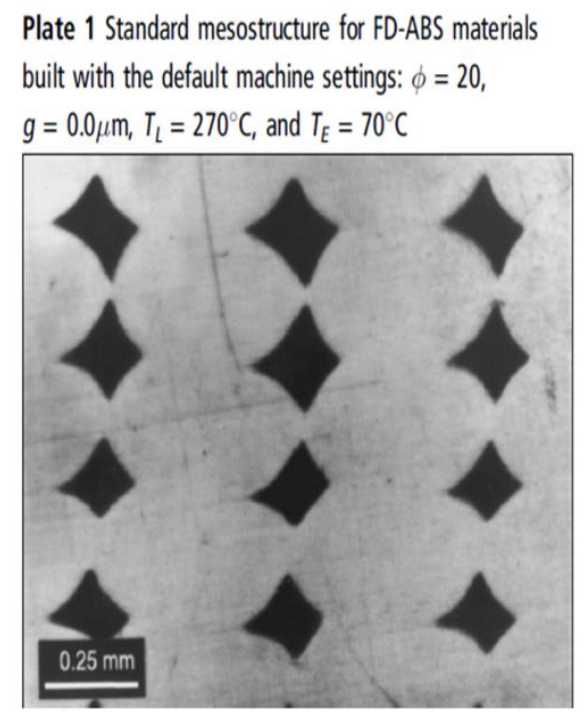

Figure 4: Mesostructure of an ME-ABS material illustrating the porous structure that may be achieved based on the raster angle and bead overlap [54].

Given the complicated mesostructure of AM parts, the scope of this standard review was expanded to include standard tests used for fiber composite materials. Fiber composites are lightweight structural materials that contain high strength fibers (E 70 GPa to $250 \mathrm{GPa}$ ) embedded in a polymer matrix material (E $3 \mathrm{GPa}$ to $4 \mathrm{GPa}$ ). The fibers carry any significant loads and the matrix is designed to provide rigidity to the fiber structure. Since the fibers are stronger in the axial direction, the resulting composites can have significantly anisotropic properties. This anisotropy has been addressed in standards by specifying the directionality of the fibers. Figure 5 shows an example of fibers oriented in different $x, y$ directions along the z-plane. If this rotation is done symmetrically, the composite laminate may be considered quasi-isotropic in material properties in the plane of the fibers. While geometry guidelines are critical for fiber composites, it is not clear whether these are valid for AM materials since stress distribution through the AM mesostructure will differ greatly from a fiber composite. 


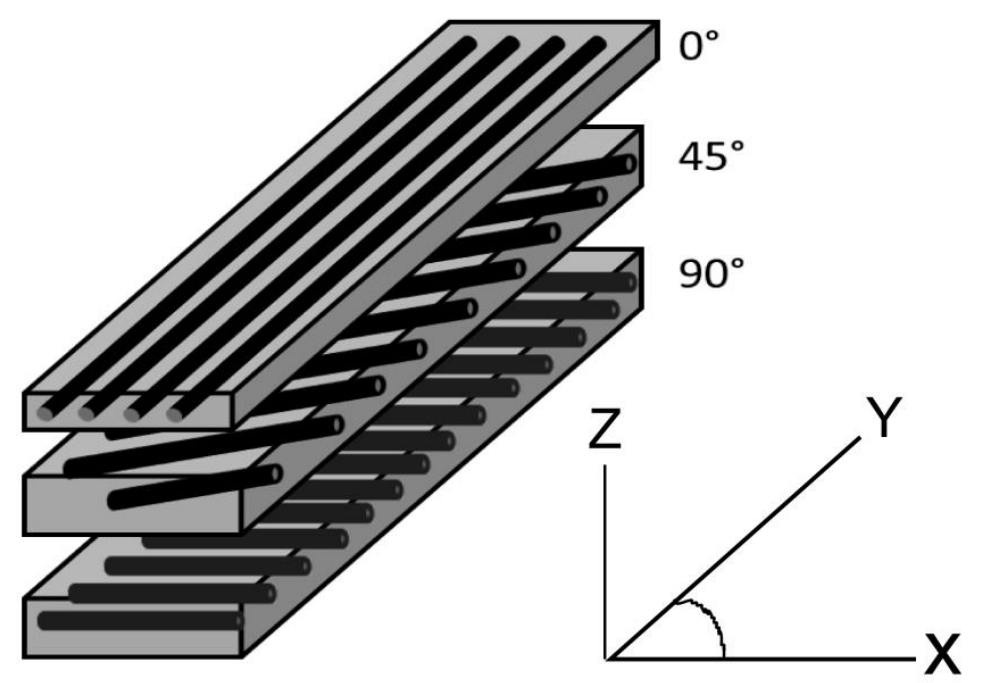

Figure 5: Graphic illustrating the directionality of fibers, through z, in a fiber composite laminate. The orientation and number of fibers controls the performance of the composite.

Mechanical properties: These properties are often defined in terms of the behavior at loads that do not produce failure or failure behavior itself. For solids, the first case is generally characterized by moduli that are defined as the stress divided by the strain. Moduli can be measured with a number of different loading modes: tension, compression, flexure, shear, or torsion [55], and in the linear region, they are proportionality constants independent of strain. The moduli of polymeric materials are functions of temperature and time. These dependencies, particularly temperature, are important. For many polymers used in additive manufacturing, these properties are often reported in the technical specification sheet in tension (or compression) and shear loading modes. Since two parameters are needed to model behavior in different loading directions, an alternative is to report Young's Modulus and Poisson's Ratio. Poisson's Ratio is the negative ratio of transverse to axial strain.

Failure Properties: As the stress increases, materials begin to fail via plastic deformation (nonlinear stress vs. strain) or brittle fracture. One approach to quantify failure behavior is by determining yield strength, ultimate strength, and impact strength. Each one of these may be defined in relationship to the mode of loading: tension, compression, flexure, shear, or torsion [55]. For many polymers used in additive manufacturing, these properties are often reported in the technical specification sheet in tension or compression loading modes. On the other hand, these parameters do not adequately characterize materials that fail by the propagation of cracks. To describe this behavior requires fracture parameters that are often not reported in the technical sheet [53]. The fracture toughness or fracture energy of the material is [55] defined in three modes (I: crack opening, II: in-plane shear, and III: out of plane shear) as shown in Figure 6. Standards are available to test in Mode I, Mode II, and mixtures of Mode I and II, although the complex shapes of many AM parts may increase the importance of Mode III. Fracture toughness is a critical factor for ME and LS created polymer parts and given the complex mesostructure and anisotropy, it may be difficult to induce purely one loading Mode for testing. 


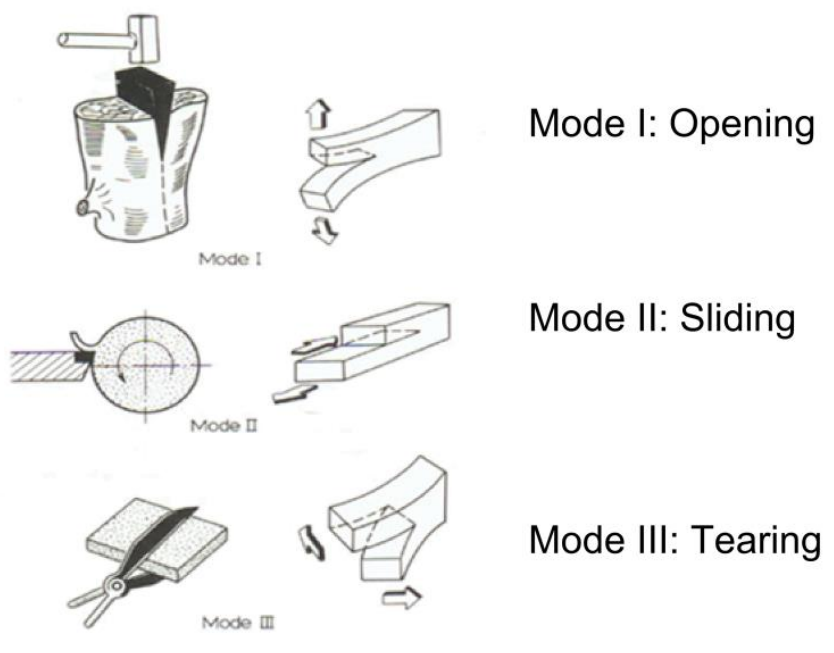

Figure 6: Three modes of crack surface displacements Mode I (opening or tensile mode), Mode II (sliding mode), and Mode III (tearing mode) copied from [56].

The terms used to define failure properties are given below:

Yield Stress/Yield Strength
Ultimate Strength
Elongation at Yield
Elongation at Break
Fracture Toughness
Fracture Energy
Impact Strength
Bearing Strength
Open Hole Compression Strength
Crack Growth Resistance Curves

Bearing and open hole tests evaluate the ability of the material to perform with an engineered flaw such as a bolt or pin in the structure.

Interlaminar properties are important for fiber reinforced composites. As shown in Figure 5, the fibers lie in a plane and provide high strength and stiffness in that direction. Although designers plan structures so the loads are in the fiber direction, unexpected events can produce loads perpendicular to this plane, which causes damage. This can significantly reduce the performance in the fiber direction, particularly compressive strength. Often the fiber-matrix interface represents the weak point of the composite because it relies on bonding between the fiber filler and the compliant matrix. Interlaminar test methods allow the user to understand the susceptibility of the material to damage between fiber layers. Unfortunately, interlaminar properties do not provide explicit engineering limits on the maximum load that a composite material can bear in off-axis loading, but tests like interlaminar fracture and short beam strength 
can indicate general ranking. For composites, standard test methods for interlaminar properties are:

\author{
Short beam strength \\ Shear modulus \\ Ultimate shear stress strength
}

Durability: Durable material properties may be quantified using several standards depending on the usage of the material. In the context of this review, durability is addressed for mechanical durability, specifically creep and fatigue. There are standards available in ASTM and ISO that define exposure conditions for moisture, temperature, and artificial sunlight exposure on materials. Creep is important for understanding the ability of the material to withstand long-term static loading. Fatigue properties are important for understanding the ability of the material to withstand cycling loading during usage. Finally, impact strength is a measure of the material to withstand high strain rate loading and evaluate the ability of the material to absorb energy and resist damage. Mechanical properties that define mechanical durability are:

\author{
Creep Modulus \\ Creep Rupture \\ Fatigue life (S-N plots/R-N plots)
}

Standards are important for mechanical and failure properties because they are the language that mitigates risk within the design and allows engineers to build structural and safety critical parts with a known performance window. The specific ASTM and ISO standards that are applicable to quantify the material properties listed above will be addressed individually.

\title{
6. Challenges for Mechanical Property Characterization:
}

While AM provides the opportunity to quickly go from design to product especially for parts that have difficult or impossible to machine features, challenges remain for predicting mechanical performance. Many AM processes differ from traditional polymer processing in that not all of the material is melted and homogenized. The AM process of depositing layers of polymeric material results in parts with anisotropic properties, residual stress, and this is a significant challenge. Researchers and Original Equipment Manufacturers (OEMs) must establish the standardized methods to determine material properties from AM processing rather than the mechanical properties of a particular design. Peer-reviewed literature has begun to highlight complexity in relating material properties, AM mesostructure, and part design for standardized testing. Despite the importance of this problem for the success of AM as a critical manufacturing process, the literature available in this area is not significantly large. Figure 7 shows the typical geometrical variables related to ME deposition geometry. 


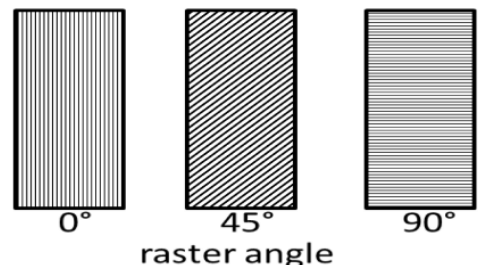

a)

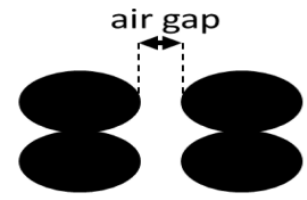

c)

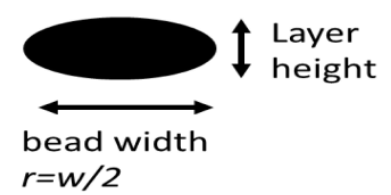

b)

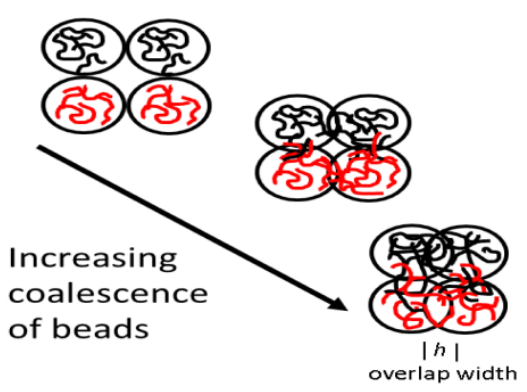

d)
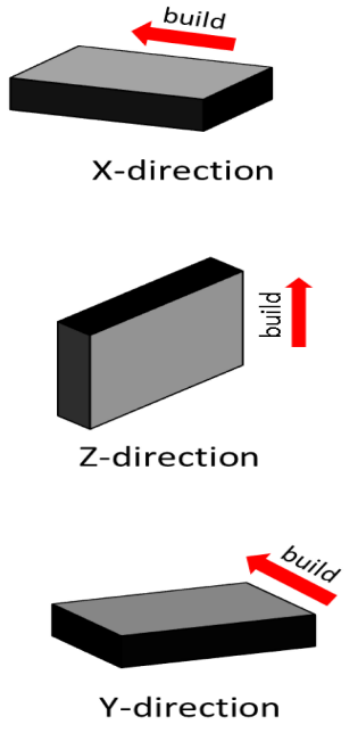

e)

Figure 7: Graphical representation of process variables related to the build geometry for additive manufacturing. a) raster angle, b) extruded filament height and layer width, c) air gap between extruded filaments, d) combinations of variables ( $\mathrm{T}$, air gap, width, height, velocity) can increase the coalescence between filaments, e) the build direction can affect the load transfer between filaments and interfaces.

The majority of studies have focused on the impact of raster angle, air gap, filament width, layer height, and build orientation to major part axis (i.e. $x, y$, or z-direction). Build orientation allows one to capture interacting factors such as filament length, temperature gradients, and nozzle velocity on mechanical properties. Many additive systems that rely on material extrusion processes allow for full infill of the deposited part, but it was not possible to compare literature studies directly. Evidence for mechanical anisotropy was more readily identified in the literature for powder bed fusion processes.

The impact of processing for anisotropic mechanical properties in material extrusion has been identified by multiple authors with ME processing of ABS polymers as a major focus [54, 57-68]. In the case of ME, AM parts exhibit inferior mechanical properties compared to the as-received polymer filament that feeds the AM extruder head and compression molding or injection molded parts constructed from this same as-received filament. Raster angle is a process parameter that influences anisotropy and strength in AM parts. Rodriquez showed reductions in modulus can range from $11 \%$ to $37 \%$ [65]. In general, parts were stronger when the beads were aligned in the loading direction for tensile loading [57, 64], mixed angles for flexure [57, 58], and orthogonal to loading for compression [67]. Ahn used twelve layers of ABS oriented in $\left[0^{\circ}\right],\left[45^{\circ} /-45^{\circ}\right],\left[0^{\circ} / 90^{\circ}\right]$ and $\left[90^{\circ}\right]$ to investigate the effect of raster angle [57]. Alignment of long fibers with the loading path increased strength, but gaps between bead layers reduced strength. Similar work in unidirectional deposition of materials supports this idea. Es-Said found that increasing raster angle lowered strength, but had little effect on modulus [59]. They also 
found that failure tended to occur in the deposition lines. As the raster angle increases the tensile properties of the material are reduced $[57,65]$. Huang has shown that tensile and shear properties of unidirectional $\mathrm{ABS}$ parts reach a minimum around raster angles of $50^{\circ}$ [61]. Similar results have been found for ME production of PC materials. Masood could achieve approximately $80 \%$ of an injected molded material by aligning the beads with loading [63]. Hill conducted a systematic study of raster angle on unidirectional parts with similar density and found that aligning the beads in the axial direction produced the best failure properties [60]. The strength could be modeled using micromechanics to account for the fusion strength.

The air gap influences void percentage, which plays a large role in determining mechanical properties. The strength of the AM part is not only derived from lines of extruded filament, but the interaction between filaments is important. The presence of voids and sharp corners increase stress within the part and failure can initiate at these features [58]. In general, minimizing the gap between filaments increases the contact area between filaments and leads to a stronger fusion interface. Rodriguez has shown that a combination of process parameters may be used to control the void space, and he could model the resulting structure using laminate theory [65]. ME relies on the thermal gradients between neighboring filaments to allow the thermoplastic polymers to diffuse and form a stronger fusion interface. These fusions have been compared to the matrix in a fiber reinforced composites because they hold the filaments together [65]. The time required to maximize bond strength between successive filaments is not immediately known from technical data sheets, but it is related to the structure of the polymer (molecular weight, glass transition temperature, crystallinity, etc.) and the thermal gradient between the new filament and the previous filaments. A guideline was developed to minimize the air gap and optimize the bead width or height to increase contact area in order to improve bond strength. Sun observed temperature profiles in ME and bead interface formation to quantify interface formation. He found that envelope temperature and convection in the build chamber have a significant effect on mesostructure [69]. Sood et al. used a response surface developed from design of experiments coupled to neural network analysis to demonstrate the non-linear behavior of printing parameters and utilized neural network modelling to predict compressive properties [67, 70]. Another empirical study led to six build rules to help designers maximize mechanical performance [57]. These studies have highlighted the complicated relationship between the build parameters, part design, and final properties.

There are examples of unintended consequences from not accounting for interacting parameters. Decreasing the bead width reduces residual stress in the filament and can increase diffusion length, but requires more laps to create the part. Residual stress is caused by the contraction of the polymer filament on cooling. In the case of semi-crystalline materials, the contraction of volume from crystallization increases residual stress at interfaces. In order to fill the space with a smaller filament width, the nozzle must complete a higher number of long passes and short passes for direction reversal. The extruding nozzle will change speed to accommodate the printing process; the corollary for sintering is laser raster speed and energy. The successive thermal cycling caused by changes in nozzle speed impacts thermal diffusion because speed changes impact residence time [70]. Another example is maximizing the temperature and filament height can lead to part distortion and surface roughness that negatively impacts appearance and mechanical properties. Orientation of the polymer during extrusion will reduce strain to failure up to $33 \%$ [58] and increase the time for polymer diffusion, but orientation has 
not been sufficiently addressed in the literature. Failure in these materials is often brittle and driven by build construction. Larger filament widths, oriented polymer within beads, and poor diffusion are all suspected to lead to inter-laminar failures facilitated by defects and surface roughness at the fusion lines. These factors need to be accounted for in models, validated through standardized testing, and incorporated into the process workflow to support AM.

It is difficult to isolate the impact of build direction on anisotropy because this is often confounded with other build parameters. Riddick et al. combined $x z, y z$, and $x y$ build directions with changes in bead length and raster angle combinations of $\left[0^{\circ}\right],\left[0^{\circ} / 90^{\circ}\right]$ and $\left[90^{\circ}\right]$ and found that the xz direction had the highest modulus $(2.67 \mathrm{GPa})$ and strength $(15.26 \mathrm{MPa})$ due to a combination of void filling and optimal raster geometry [64]. Others have found that build paths that maximize alignment of fibers in the loading direction increased strength [58]. There are a small number of studies investigating the durability of ME parts. One study showed that a $\mathrm{PEI} / \mathrm{PC}$ blend aged at room temperature and water was stable over 52 weeks and relatively insensitive to short time exposure to aerospace solvents [71].

Similar challenges exist for powder bed fusion processing and concern the impact of thermal gradients and void space in the part. If the layer heights are too large, the powder acts as a thermal insulator which prevents heat transfer to the lower powder layer. This can reduce the consolidation of molten material into the gaps below and inter-diffusion of polymer species [7]. The crystallization temperature of the material is important for the increase of bonding between the molten beads [72]. Shrinkage has been shown to depend on different build parameters based on laser raster direction, where laser power and scan length are critical for $x$-direction while hatch spacing and part bed temperature are critical for the $z$-direction [73]. Recycled powder presents a challenge for laser sintering. There is potential for polymer aging and crosslinking for a material that has been previously processed, but not sintered. This aging increases melt viscosity and prevents flow, which creates weak interfaces and defects within the part. Thermal control of the powder bed is also important. Improper powder bed temperature leads to interruption of the thermal gradients during the sintering process which can lead to reduction in performance [72]. Leigh found that increasing the size of the polymer interface, characterized by an $h / r$ ratio (see Figure $6 b$ and $6 d$ ) increased the yield stress and ultimate tensile strength [7], but there was limited information found on durability studies for LS parts. One study showed that these materials exhibited a slight drop in mechanical properties when subjected to aggressive automotive fluids, similar to the performance of the base polymers [74].

In the case of material jetting, the kinetics of the photo-polymerization reaction and thermal annealing of the part must lead to uniform cross-linking between successive layers. Lee found that 3D printing produces anisotropic materials with much lower compressive strength [62]. Additional challenges include the presence of additives, printing on an over-cured surface, and the proprietary knowledge of formulations. Similar to thermoplastic technologies, the print resin formulations are not known to users. Therefore, the impact of reactants, catalysts, and monomer molecular weight are difficult to separate. The photochemistry literature of dental resins, photolithographic patterning, and radiation curing is expected to contain a wealth of prior art concerning optimization of formulations and processing. A nanocomposite deposition system that produced composite parts, but requires a machining step after successive layers had mechanical performance closer to ME produced parts, although the materials remained 
anisotropic. Ang et al investigated the impact of trapped volume (voids) and trapped material for various rapid prototyping metrologies [10]. They found that these artifacts affect the functionality and dimensional stability of the final part, but they did not measure the mechanical properties.

Research is moving towards a better understanding of raw material microstructure, the physics and chemistry of polymer fusion and photopolymerization, and utilizing composite modeling to understand anisotropic properties as a function of the AM mesostructure. Fusion and coalescence have been presented in terms of a Frenkel-Eshelby formulation [61]. Huang was able to combine a force model with an understanding of the magnitude of coalescence to predict the performance of ABS. Composite models have been used to understand the deformation of these materials with an eye toward design variables and identifying fusion contributions to properties $[58,60,65]$. Many of these studies have been done on industrial or consumer-grade equipment [68], and it is not clear how the structure of the raw materials and tolerances of the process variables were controlled. There is much work that is required to drive current research towards industrially relevant AM standards.

\section{Overview of Standard Testing Methods}

There are two standards groups addressing AM. In ASTM committee F42 has jurisdiction over Additive Manufacturing Technologies and subcommittee F42.05 addresses materials and processes specifically [75]. TC 261 promulgates standards in the AM fields for the ISO. Both of the groups currently address mechanical testing of AM materials and parts via reference to established standards [76]. The following analysis describes the applicability of existing standards to mechanical testing of polymer AM materials and parts.

\section{1. $\underline{\text { Tension }}$}

These standards are classified for plastics (ASTM D638 [44], ISO 527-2 [77]) and composites (ASTM D3039 [78], ISO 527-4 [79, 80]). The standards utilize dog-bone or end tab specimens whose geometry is based on the thickness of the sample or the type of composite. Tension measurements provide Young's modulus, Poisson's ratio, Yield Stress, Strength, and Elongation to Break. The standards for composites address the orientation of fibers within a composite, but the applicability of such standards to AM materials has not been thoroughly described in the literature. Ahn found that the ASTM D638 type I sample geometry caused premature failure of specimens. Early failure was caused by a stress concentration within the radius of the dog bone near the gauge length. This area of specimens contained the ends of filaments, which caused excessive shear. The authors switched to the ASTM D3039 geometry to alleviate the problem. However, this was the only reference found with this problem. ISO 458 [81], which was not reviewed, provides the test standard for the stiffness of a material under torsion.

\section{2. $\quad$ Flexure}

ASTM D790 [45] and ISO 178 [82] are equivalent standards that utilize a three-point bend method to measure the flexural modulus, flexural strength, flexural stress and strain at break within a $5 \%$ strain limit. If the strain limit is not met, then ASTM D6272 [83], which is a four- 
point method, is used to increase the chance of achieving a failure measurement. This test reduces the stress concentration associated with the center roller in a three point test. These standards are applicable for unreinforced and reinforced materials. For composites containing high modulus fibers, ASTM D7264 [84] should be used for testing. The standard does not address the specific challenges for AM materials that may have anisotropic properties.

\section{3. $\quad$ Compression}

The applicable standards for compression measurements are ASTM D695 [48] and ISO 604 [85]. ASTM D3410 [86] and ISO 14126 [87] are specific to compression of a fiber reinforced composite in-plane direction. The standards provide measurement of compressive modulus, compressive yield stress, compressive strength at failure, and compressive strain at failure. There are geometrical restrictions for the diameter and height of the sample.

\section{4. $\underline{\text { Shear }}$}

There are a number of different standard tests to measure the shear modulus and strength of materials. The fiber reinforced composite standards (ISO 14129 [88], ISO 14130 [89], ASTM D2344 [90], and ASTM D3518 [91]) are not directly applicable to AM. These methods are developed for polymers reinforced with high strength fibers or textiles in specific orientations to the loading direction. The standards require determination of specific interlaminar failure modes between the aligned fibers. These types of samples are not typically manufactured in AM. There are also two notched specimen standards ASTM D7078 [92] and ASTM D3846 [93] for measuring shear properties. These standards utilize specimens with specific notch geometries and defined alignment of the fiber reinforcement. These test methods may not be directly applicable to AM manufactured materials for two reasons. First, AM produced parts do not possess the large ratio of moduli and failure strength in different directions that is found in fiber composites, therefore the mechanics of load distribution and crack propagation will be different in an AM material. Second, composite laminates may be manufactured with sharp initiation cracks in the matrix between the fiber layers. These cracks increase the precision of the test used to measure a material failure property. The current thermal processing methods in AM are not conducive to intentionally producing a well-defined, sharp initiation crack, and this will hinder the ability to characterize failure behavior. There are methods to introduce a sharp crack into a material. Fatigue, which is used for metals, does not work for polymeric materials, and the use of a sharp edge, such as razor blades, may not produce a proper crack in AM parts.

There are only two shear standards that are directly applicable to AM. These are ASTM D4255 [94] and ISO 15310 [95] to determine the shear modulus of plastics and fiber reinforced materials, respectively. These standards allow for testing isotropic materials, but there is no guidance for testing materials constructed via AM.

\section{5. $\quad$ Creep}

Creep measurement standards provide the methodology to measure dimensional changes in samples under load as a function of different exposure environments such as temperature, aqueous, or surfactant solutions. There are a variety of loading environments: tensile, compression, flexure, and solutions. ASTM D2990-09 [49] references ASTM D543 Practices for 
evaluating the resistance of plastics to chemical reagents for testing in environmental conditions [96] that specifies solution composition for sample immersion. The ISO standard equivalent is ISO 899 [97, 98]. There are restrictions on the ratio of the length to the cross-section. The method recommends testing at a minimum of two different test temperatures within the use range of the material to understand the effect of temperature. Loading at seven stress levels to produce creep-rupture at different times up to $3000 \mathrm{~h}$ provides a measure of long term performance. Design data for creep is obtained by testing materials at different stress levels to produce $1 \%$ strain in $1000 \mathrm{~h}$. There is no guidance provided for anisotropic samples, such as fiber composites.

\section{6. $\quad$ Fatigue}

ASTM D7774 [99] is the standard for uniaxial loading with no equivalent in ISO. The test frequency can range between $(1-25) \mathrm{Hz}$, but less than $5 \mathrm{~Hz}$ is recommended. This frequency reduce the chances of heat generation in the sample. The test method allows generation of a stress or strain as a function of cycles, with the fatigue limit characterized by failure of the specimen or reaching $10^{7}$ cycles. The $10^{7}$ cycle value is chosen to limit the test time, but depending on the applications this may or may not be the best choice. The maximum and minimum stress or strain levels are defined through an $R$ ratio. The $R$ ratio is the ratio of minimum to maximum stress or displacement that the material is cycled through during testing. Testing is conducted within the elastic limit of the material. For this standard, samples may be loaded in either tension or compression.

ASTM D7791 [100] and ISO 13003 [101] are the test methods for flexure fatigue of plastics. The subject matter of the tests is similar, but technically different. In both tests, the loading is sinusoidal. ASTM D7791 utilizes either a three-point or four-point loading with cycling occurring in positive and negative directions. Control occurs in either stress or strain versus cycle number. The $\mathrm{R}$ ratio is -1 and the stress or strains do not exceed the proportional limit. The test ends at either failure or reaching $10^{7}$ cycles.

ISO 13003 calculates the ultimate tensile/flexural strength for fatigue loading rate. In strain control, the end of the test is listed as the damage level related to specimen stiffness reduction of $20 \%$. Four fatigue levels are tested in accordance with the fatigue life of interest or the range of stress/strain of interest. Similarly, strain or stress vs. the number of cycles is reported. Neither standard addressed the challenges associated with AM processing inducing anisotropy within the materials.

There are two standards that relate to fatigue delamination or crack propagation. These are ISO 15850 [102] and ASTM D6115 [103]. Both of these standards are specifically applicable to the measurement of fracture energy in the interlaminar region of a fiber composite. Similar to other composite specific standards, it is not clear whether AM materials would meet the fracture mechanics assumptions that support these standards.

\section{7. $\quad$ Fracture Toughness}

Fracture toughness measurements are used to determine the energy required to initiate crack propagation from a precrack within a material or composite. These values are used for designing 
parts and developing materials. These standards often require the development of a sharp precrack within a material, application of load, and monitoring of the load, displacement, and crack progression. A linear elastic fracture mechanics analysis was used to develop measurements of fracture energy $\left(\mathrm{G}_{\mathrm{iC}}\right)$ and fracture toughness $\left(\mathrm{K}_{\mathrm{iC}}\right)$, where $i$ indicates the mode of loading I, II, or III, see Figure 6. In composites, these measurements are used to determine the fracture toughness between plies containing high modulus fibers or textiles. In polymers, this test provides material properties for engineering design. These often require the insertion of a pre-crack material to create the sharp crack, which may be problematic given the dimensional limitations for AM processes.

ISO 15024 [104] and ASTM D5528 [105] are specifically for fiber reinforced composites. These standards are used to generate crack growth resistance curves (R-curves), which are measures of delamination resistance through the composite. They are not directly applicable to current AM manufacturing because continuous fibers are not present. It is not immediately clear whether these concepts could work for evaluation of the mesostructure or fusion zone in an AM material. ISO 29221 [106] is a standard for the plane-strain crack-arrest toughness in a compact tension specimen. This requires a sharp initial crack and a groove in the sample to limit the location of crack growth across the specimen. The challenges in AM relate to the dimensional resolution of the AM process and whether the impact of build direction on the propagation of the crack.

ISO 13586 [107] applies to the measurement of rigid and semi-rigid thermoplastics and discontinuous fiber composites. The biggest question is the influence of the mesostructure created during the AM process to measure a material property. An amendment to ISO 13586 [108] provides testing injected molded composites with directions for testing longitudinal and transverse processing directions. This would be an acceptable place to start for determining the applicability of this test standard to AM parts.

ASTM D6068 [109] is for the development of J-R curves for plastic materials. This is a specific method to develop an understanding of parameters for cohesive zone modeling of crack propagation. The method requires optical measurement of crack growth. This method may be applicable to specific types of deposition processes such as powder bed fusion of clear thermoplastics or material jetting of clear photopolymers, but it would still require the machining of a crack into the sample.

\section{8. $\quad$ Impact}

ISO 179 [110, 111] and ASTM D6110 [112] describe the method for the Charpy impact test. ISO 180 [113] and ASTM D256 [46] are the methods for Izod impact testing. Impact testing is mentioned with technical data sheets for many AM relevant polymers. It is not clear how the AM material is prepared and oriented for impact testing from the material data sheets. The main differences between the tests are the material position and notch placement. The load is applied rapidly by hitting the sample with a heavy striker. In the Izod test, the material is in a vertical position and the notch faces the striker. In the Charpy test, the material is horizontal with the notch away from the striker. The Charpy notch may be a V or a U-shaped notch. Similar to fracture toughness testing, it is not clear whether the notch may be sufficiently deposited into the AM part or should be machined at a later date. 


\section{9. $\quad$ Bearing Strength and Open Hole Compression}

These tests represent functional strength tests for composites that will be fastened using bolts. It can also provide some insight into the effects of a damage region on performance. The specific standards are ASTM D953-10 [114], ASTM D5961 [115], and ASTM D6484 [116]. In ISO, the specific standards are ISO 12815 [117] and ISO 12817 [118]. The tests develop design parameters for integrating composites materials together and within structures. Currently, no demand was observed in the literature for these types of measurement standards by the AM community, which is not to say the demand does not exist. It is feasible that as AM materials are integrated with other structures such as in the human body, the community will need to understand the impact of part design on load carrying capability and whether the part will deform over time. Current standards should be directly applicable, but there should be comments provided on material isotropy.

\section{Standards Applicability Assessment}

In the following charts, ASTM and ISO standards were evaluated to determine their applicability to additive manufacturing. One of three classifications is given for each standard. If special consideration should be noted for the standard, specific notes are provided. The list covers standards for plastic materials and composites. The following labels are used for assessing applicability of the standard:

- $\quad$ YES - The standard should be applicable for additive manufacturing with very minimal or no modifications.

- $\quad$ YES WITH GUIDANCE - The standard should be generally applicable for additive manufacturing, but there may be limits on its applicability, and some modifications or additional considerations are probably needed. These include:

○ Geometrical limits on test specimens

- Required post-processing such that specimens built via additive manufacturing meet the requirements of the standard; this typically includes surface finish, dimensional requirements, or pre-crack requirements.

- Material isotropy requirements. AM specimens often have inherent anisotropy. The measurement methods that specify applicability for isotropic materials may still work, but the measured results may have larger uncertainties. This includes consideration of separating material properties from part properties.

- Application specific considerations, such as elevated testing temperatures or immersion environments.

- $\quad \mathrm{NO}$ - The standard requires specimens that cannot be built via AM, even major modifications may not be adequate, another method is better suited for the measurement or the measurement simply is not applicable.

In some cases standards were identified and listed in the applicability index, but they were not specifically reviewed. 


\begin{tabular}{|c|c|c|c|}
\hline Standard Designation & Standard Name & $\begin{array}{l}\text { Applicable for } \\
\text { AM Testing } \\
\end{array}$ & Notes \\
\hline \multicolumn{4}{|l|}{ Tensile } \\
\hline ISO $527-2: 2012$ & $\begin{array}{l}\text { Plastics -- Determination of } \\
\text { tensile properties -- Part 2: Test } \\
\text { conditions for moulding and } \\
\text { extrusion plastics }\end{array}$ & $\begin{array}{l}\text { Yes with } \\
\text { guidance }\end{array}$ & $\begin{array}{l}\text { Equivalent to ASTM D638. Broken into } 5 \text { parts to account } \\
\text { for different types of samples (i.e. film, isotropic fiber } \\
\text { composites, unidirectional composites) }\end{array}$ \\
\hline ASTM D638 - 10 & $\begin{array}{l}\text { Standard Test Method for } \\
\text { Tensile Properties of Plastics }\end{array}$ & $\begin{array}{l}\text { Yes with } \\
\text { guidance }\end{array}$ & $\begin{array}{l}\text { Basic test method for producing tensile properties of } \\
\text { plastics. Several different dog-bone geometry available. } \\
\text { High strength reinforcement requires ASTM D3039 }\end{array}$ \\
\hline ASTM D3039 & $\begin{array}{l}\text { Standard Test Method for } \\
\text { Tensile Properties of Polymer } \\
\text { Matrix Composite Materials }\end{array}$ & $\begin{array}{l}\text { Yes with } \\
\text { guidance }\end{array}$ & $\begin{array}{l}\text { Basic test method for producing tensile properties of high } \\
\text { modulus fiber composites. Requires a rectangular shape } \\
\text { specimen. Not clear additive materials meet reinforcement } \\
\text { criteria, but rectangular geometry alleviates defects }\end{array}$ \\
\hline ISO 527-4:1997 & $\begin{array}{l}\text { Determination of tensile } \\
\text { properties -- Part } 4 \text { : Test } \\
\text { conditions for isotropic and } \\
\text { orthotropic fibre-reinforced } \\
\text { plastic composites }\end{array}$ & $\begin{array}{l}\text { Yes with } \\
\text { guidance }\end{array}$ & $\begin{array}{l}\text { Specific to fiber reinforced composites. Specific } \\
\text { reinforcements and manufacturing processes could require } \\
\text { use of this part. }\end{array}$ \\
\hline ISO 527-5:2009 & $\begin{array}{l}\text { Determination of tensile } \\
\text { properties -- Part 5: Test } \\
\text { conditions for unidirectional } \\
\text { fibre-reinforced plastic } \\
\text { composites }\end{array}$ & No & $\begin{array}{l}\text { Specific to fiber reinforced composites with unidirectional } \\
\text { reinforcement. Not applicable given current AM } \\
\text { technologies for composite production. }\end{array}$ \\
\hline \multicolumn{4}{|l|}{ Torsion } \\
\hline ISO $458-1: 1985$ & $\begin{array}{l}\text { Determination of stiffiness in } \\
\text { torsion of flexible materials -- } \\
\text { Part 1: General method }\end{array}$ & & Not reviewed \\
\hline \multicolumn{4}{|l|}{ Flexure } \\
\hline ISO $178: 2010$ & $\begin{array}{l}\text { Plastics -- Determination of } \\
\text { flexural properties }\end{array}$ & $\begin{array}{l}\text { Yes with } \\
\text { guidance }\end{array}$ & Equivalent to ASTM D790. \\
\hline
\end{tabular}




\begin{tabular}{|c|c|c|c|}
\hline Standard Designation & Standard Name & $\begin{array}{l}\text { Applicable for } \\
\text { AM Testing }\end{array}$ & Notes \\
\hline \multicolumn{4}{|l|}{ Flexure Cont'd } \\
\hline ASTM D6272- 10 & $\begin{array}{l}\text { Standard Test Method for } \\
\text { Flexural Properties of } \\
\text { Unreinforced and Reinforced } \\
\text { Plastics and Electrical Insulating } \\
\text { Materials by Four-Point } \\
\text { Bending }\end{array}$ & $\begin{array}{l}\text { Yes with } \\
\text { guidance }\end{array}$ & $\begin{array}{l}\text { Similar to D790 except a four point method that might work } \\
\text { better for materials that do not fail within strain limits of } \\
\text { D790. }\end{array}$ \\
\hline ASTM D7264 / D72€ & $\begin{array}{l}\text { Standard Test Method for } \\
\text { Flexural Properties of Polymer } \\
\text { Matrix Composite Materials }\end{array}$ & No & $\begin{array}{l}\text { Specific to continuous fiber reinforced composites. Not } \\
\text { applicable given current AM technologies for composite } \\
\text { production. }\end{array}$ \\
\hline ASTM D790 - 10 & \begin{tabular}{|l|} 
Standard Test Methods for \\
Flexural Properties of \\
Unreinforced and Reinforced \\
Plastics and Electrical Insulating \\
Materials \\
\end{tabular} & $\begin{array}{l}\text { Yes with } \\
\text { guidance }\end{array}$ & $\begin{array}{l}\text { Basic method for testing the flexure properties of } \\
\text { unreinforced and reinforced plastics using three point bend. } \\
\text { Requires material to fail in outer surface with } 5 \% \text { of strain } \\
\text { limit for flexural strength. Measured modulus will be } \\
\text { impacted by layer stacking. }\end{array}$ \\
\hline \multicolumn{4}{|l|}{ Compression } \\
\hline ISO $14126: 1999$ & $\begin{array}{l}\text { Fibre-reinforced plastic } \\
\text { composites -- Determination of } \\
\text { compressive properties in the in- } \\
\text { plane direction }\end{array}$ & No & $\begin{array}{l}\text { Test method to determine the compressive properties of a } \\
\text { fiber reinforced plastic matrix composite in the in-plane } \\
\text { direction. }\end{array}$ \\
\hline ASTM D695 - 10 & $\begin{array}{l}\text { Standard Test Method for } \\
\text { Compressive Properties of } \\
\text { Rigid Plastics }\end{array}$ & $\begin{array}{l}\text { Yes with } \\
\text { guidance }\end{array}$ & $\begin{array}{l}\text { Basic test method for producing compressive properties of } \\
\text { plastic right cylinder with } L=2 \mathrm{D} \text {. Guidance required on } \\
\text { building of AM test sample. }\end{array}$ \\
\hline $\begin{array}{l}\text { ASTM D3410/ } \\
\text { D3410M - 03(2008) }\end{array}$ & $\begin{array}{l}\text { Standard Test Method for } \\
\text { Compressive Properties of } \\
\text { Polymer Matrix Composite } \\
\text { Materials with Unsupported } \\
\text { Gage Section by Shear Loading }\end{array}$ & No & $\begin{array}{l}\text { Test method for in-plane compressive properties of polymer } \\
\text { matrix composites using high modulus fibers (i.e. } \\
\text { unidirectional tape and short fiber composites). Requires } \\
\text { elastic properties orthotropic to test direction. }\end{array}$ \\
\hline ISO 604 & $\begin{array}{l}\text { Plastics -- Determination of } \\
\text { compressive properties }\end{array}$ & $\begin{array}{l}\text { Yes with } \\
\text { guidance }\end{array}$ & $\begin{array}{l}\text { Test method for measuring compressive properties of plastic } \\
\text { materials. Guidance required for building of AM test } \\
\text { samples. }\end{array}$ \\
\hline
\end{tabular}




\begin{tabular}{|c|c|c|c|}
\hline Standard Designation & Standard Name & $\begin{array}{l}\text { Applicable for } \\
\text { AM Testing }\end{array}$ & Notes \\
\hline \multicolumn{4}{|l|}{ Shear } \\
\hline ISO 14129:1997 & $\begin{array}{l}\text { Fibre-reinforced plastic } \\
\text { composites -- Determination of } \\
\text { the in-plane shear stress/shear } \\
\text { strain response, including the in- } \\
\text { plane shear modulus and } \\
\text { strength, by the plus or minus } 45 \\
\text { degree tension test method [in } \\
\text { plane] }\end{array}$ & No & Equivalent to ASTM D3518 \\
\hline $\begin{array}{l}\text { ASTM D3518 / } \\
\text { D3518M-13 }\end{array}$ & $\begin{array}{l}\text { Standard Test Method for In- } \\
\text { Plane Shear Response of } \\
\text { Polymer Matrix Composite } \\
\text { Materials by Tensile Test of a } \\
\pm 45^{\circ} \text { Laminate }\end{array}$ & No & $\begin{array}{l}\text { Basic test method to test polymer matrix composites } \\
\text { reinforced with high strength fibers arranged in a } \pm 45^{\circ} \\
\text { direction. This test method the mechanical strength of } \\
\text { composites to off-axis loading. }\end{array}$ \\
\hline ISO $14130: 1997$ & $\begin{array}{l}\text { Fibre-reinforced plastic } \\
\text { composites -- Determination of } \\
\text { apparent interlaminar shear } \\
\text { strength by short-beam method }\end{array}$ & No & $\begin{array}{l}\text { Procedure to determine the apparent interlaminar shear } \\
\text { strength using short beam shear method. This test does not } \\
\text { provide design values, only a qualitative ranking of shear } \\
\text { strength. While this test is designed to test anisotropic } \\
\text { materials, it is not suitable for AM materials. }\end{array}$ \\
\hline $\begin{array}{l}\text { ASTM D2344 / } \\
\text { D2344M - } 13\end{array}$ & $\begin{array}{l}\text { Standard Test Method for Short } \\
\text { Beam Strength of Polymer } \\
\text { Matrix Composite Materials } \\
\text { and Their Laminates }\end{array}$ & No & $\begin{array}{l}\text { Procedure to determine the apparent interlaminar shear } \\
\text { strength using short beam shear method. This test does not } \\
\text { provide design values, only a qualitative ranking of shear } \\
\text { strength. While this test is designed to test anisotropic } \\
\text { materials, it is not suitable for AM materials. Small } \\
\text { differences between ISO } 14130 \text {. }\end{array}$ \\
\hline ISO $15310: 1999$ & $\begin{array}{l}\text { Fibre-reinforced plastic } \\
\text { composites -- Determination of } \\
\text { the in-plane shear modulus by } \\
\text { the plate twist method }\end{array}$ & $\begin{array}{l}\text { Yes with } \\
\text { guidance }\end{array}$ & $\begin{array}{l}\text { Test Method for determining the in-plane shear modulus } \\
\left(\mathrm{G}_{12}\right) \text { of fiber reinforced plastic composites using a standard } \\
\text { plate specimen. When applied to isotropic materials, the } \\
\text { measured shear modulus is independent of direction. }\end{array}$ \\
\hline
\end{tabular}




\begin{tabular}{|c|c|c|c|}
\hline Standard Designation & Standard Name & $\begin{array}{l}\text { Applicable for } \\
\text { AM Testing }\end{array}$ & Notes \\
\hline \multicolumn{4}{|l|}{ Shear cont'd } \\
\hline $\begin{array}{l}\text { ASTM D4255/ } \\
\text { D4255M - 01(2007) }\end{array}$ & $\begin{array}{l}\text { Standard Test Method for In- } \\
\text { Plane Shear Properties of } \\
\text { Polymer Matrix Composite } \\
\text { Materials by the Rail Shear } \\
\text { Method }\end{array}$ & No & $\begin{array}{l}\text { Test method to determine the in-plane shear properties of } \\
\text { high modulus composites. The standard specific loading } \\
\text { geometries for different composite lay-ups or orthotropic } \\
\text { non-woven materials. This orientation my not be possible in } \\
\text { AM manufacturing with discontinuous fiber reinforcement. }\end{array}$ \\
\hline ASTM D7078 / D707 & $\begin{array}{l}\text { Standard Test Method for } \\
\text { Shear Properties of Composite } \\
\text { Materials by V-Notched Rail } \\
\text { Shear Method }\end{array}$ & No & $\begin{array}{l}\text { Test method to determine the in-plane shear properties of } \\
\text { high modulus composites. This method utilizes a V-notch } \\
\text { specimen. Designed for oriented fibers and short fiber } \\
\text { reinforcement with the majority of fibers randomly oriented. } \\
\text { This orientation my not be possible in AM manufacturing } \\
\text { with discontinuous fiber reinforcement. }\end{array}$ \\
\hline ASTM D3846- 08 & $\begin{array}{l}\text { Standard Test Method for In- } \\
\text { Plane Shear Strength of } \\
\text { Reinforced Plastics }\end{array}$ & No & $\begin{array}{l}\text { Test Method to measure in-plane shear strength of a fiber } \\
\text { reinforced plastic. Method utilizes a notched specimen } \\
\text { loaded in compression. Intended for random fiber } \\
\text { placement. Not suitable for AM materials. }\end{array}$ \\
\hline \multicolumn{4}{|l|}{ Creep } \\
\hline ISO $899-1: 2003$ & $\begin{array}{l}\text { Plastics -- Determination of } \\
\text { creep behaviour -- Part 1: } \\
\text { Tensile creep }\end{array}$ & $\begin{array}{l}\text { Yes with } \\
\text { guidance }\end{array}$ & Equivalent to ASTM D2990. Tensile geometry \\
\hline ISO $899-2: 2003$ & $\begin{array}{l}\text { Plastics -- Determination of } \\
\text { creep behaviour -- Part 2: } \\
\text { Flexural creep by three-point } \\
\text { loading }\end{array}$ & $\begin{array}{l}\text { Yes with } \\
\text { guidance }\end{array}$ & Equivalent to ASTM D2990. Three point bend geometry \\
\hline ASTM D2990-09 & $\begin{array}{l}\text { Standard Test Methods for } \\
\text { Tensile, Compressive, and } \\
\text { Flexural Creep and Creep- } \\
\text { Rupture of Plastics }\end{array}$ & $\begin{array}{l}\text { Yes with } \\
\text { guidance }\end{array}$ & $\begin{array}{l}\text { Test method to measure the creep and creep rupture } \\
\text { behavior of plastics in different environmental conditions. } \\
\text { Tension loading recommended for creep rupture. Specimen } \\
\text { geometry defined in D638. Does not address measurements } \\
\text { of reinforced composites. }\end{array}$ \\
\hline
\end{tabular}




\begin{tabular}{|c|c|c|c|}
\hline Standard Designation & Standard Name & $\begin{array}{l}\text { Applicable for } \\
\text { AM Testing }\end{array}$ & Notes \\
\hline \multicolumn{4}{|l|}{ Fatigue } \\
\hline ISO 13003:2003 & $\begin{array}{l}\text { Fibre-reinforced plastics -- } \\
\text { Determination of fatigue } \\
\text { properties under cyclic loading } \\
\text { conditions }\end{array}$ & $\begin{array}{l}\text { Yes with } \\
\text { guidance }\end{array}$ & $\begin{array}{l}\text { This international standard defines the general procedures } \\
\text { for fatigue testing of fibre-reinforced plastic composites } \\
\text { under cyclic loading conditions of constant amplitude and } \\
\text { constant frequency. Test carried out at constant load, } \\
\text { constant strain amplitude, or constant displacement. No } \\
\text { guidance given for fiber directions in relation to loading. } \\
\text { Similar to ASTM D7774, but not equivalent. }\end{array}$ \\
\hline ISO 15850:2014 & $\begin{array}{l}\text { Determination of tension-tension } \\
\text { fatigue crack propagation -- } \\
\text { Linear elastic fracture mechanics } \\
(\text { LEFM) approach }\end{array}$ & & Not reviewed \\
\hline ASTM D7774 - 12 & $\begin{array}{l}\text { Standard Test Method for } \\
\text { Flexural Fatigue Properties of } \\
\text { Plastics }\end{array}$ & $\begin{array}{l}\text { Yes with } \\
\text { guidance }\end{array}$ & $\begin{array}{l}\text { Test method for fatigue properties of rigid and semi-rigid } \\
\text { plastics cyclically loaded equally in the positive and negative } \\
\text { directions. No guidance given for testing anisotropic } \\
\text { materials and composites. }\end{array}$ \\
\hline ASTM D7791 - 12 & $\begin{array}{l}\text { Standard Test Method for } \\
\text { Uniaxial Fatigue Properties of } \\
\text { Plastics }\end{array}$ & $\begin{array}{l}\text { Yes with } \\
\text { guidance }\end{array}$ & $\begin{array}{l}\text { Test method for fatigue properties of rigid and semi-rigid } \\
\text { plastics cyclically loaded equally in the positive and negative } \\
\text { directions uniaxial loading. Utilizes rectangular or cylindrical } \\
\text { geometry. }\end{array}$ \\
\hline $\begin{array}{l}\text { ASTM D6115 - } \\
97(2011)\end{array}$ & $\begin{array}{l}\text { Standard Test Method for } \\
\text { Mode I Fatigue Delamination } \\
\text { Growth Onset of Unidirectional } \\
\text { Fiber-Reinforced Polymer } \\
\text { Matrix Composites }\end{array}$ & No & Not applicable to current AM methods. \\
\hline
\end{tabular}




\begin{tabular}{|c|c|c|c|}
\hline Standard Designation & Standard Name & $\begin{array}{l}\text { Applicable for } \\
\text { AM Testing }\end{array}$ & Notes \\
\hline \multicolumn{4}{|l|}{ Fracture Toughness } \\
\hline ISO $15024: 2001$ & $\begin{array}{l}\text { Fibre-reinforced plastic } \\
\text { composites -- Determination of } \\
\text { mode I interlaminar fracture } \\
\text { toughness, GIC, for } \\
\text { unidirectionally reinforced } \\
\text { material }\end{array}$ & No & $\begin{array}{l}\text { Test method to measure the mode I interlaminar fracture } \\
\text { toughness (critical energy release rate), GIC, of } \\
\text { unidirectional fibre-reinforced plastic composites using a } \\
\text { double cantilever beam (DCB) specimen. Specific to } \\
\text { unidirectional composites. Not clear AM capable of making } \\
\text { sample geometry and anisotropy may render test ineffective. }\end{array}$ \\
\hline ASTM D5528- 13 & $\begin{array}{l}\text { Standard Test Method for } \\
\text { Mode I Interlaminar Fracture } \\
\text { Toughness of Unidirectional } \\
\text { Fiber-Reinforced Polymer } \\
\text { Matrix Composites }\end{array}$ & No & $\begin{array}{l}\text { Test method to measure the mode I interlaminar fracture } \\
\text { toughness (critical energy release rate), GIC, of } \\
\text { unidirectional fibre-reinforced plastic composites using a } \\
\text { double cantilever beam (DCB) specimen. Specific to } \\
\text { unidirectional composites. Not clear AM capable of making } \\
\text { sample geometry and anisotropy may render test ineffective. }\end{array}$ \\
\hline ISO $13586: 2000$ & $\begin{array}{l}\text { Determination of fracture } \\
\text { toughness (GIC and KIC) -- } \\
\text { Linear elastic fracture mechanics } \\
\text { (LEFM) approach }\end{array}$ & $\begin{array}{l}\text { Yes with } \\
\text { guidance }\end{array}$ & $\begin{array}{l}\text { Test method to determine fracture toughness in mode I } \\
\text { loading for rigid and semi-rigid thermoplastics and } \\
\text { thermosets. Requires machining of sample, but AM might } \\
\text { produce initial geometry. Not clear the impact of build } \\
\text { parameters on test results. }\end{array}$ \\
\hline $\begin{array}{l}\text { ISO } \\
13586: 2000 / \text { And } \\
1: 2003\end{array}$ & $\begin{array}{l}\text { Guidelines for the testing of } \\
\text { injection-moulded plastics } \\
\text { containing discontinuous } \\
\text { reinforcing fibres }\end{array}$ & $\begin{array}{l}\text { Yes with } \\
\text { guidance }\end{array}$ & $\begin{array}{l}\text { Guidelines to apply ISO } 13586 \text { to composites. Orientation } \\
\text { of fibers within the composite can affect the results. } \\
\text { Guidance given for testing toughness dependence of test } \\
\text { direction and utilizing this information to compare } \\
\text { performance. Yield stress should be taken from } \\
\text { compression testing. It is not clear the impact of AM build } \\
\text { parameters on further influencing crack growth. }\end{array}$ \\
\hline
\end{tabular}




\begin{tabular}{|c|c|c|c|}
\hline Standard Designation & Standard Name & $\begin{array}{l}\text { Applicable for } \\
\text { AM Testing }\end{array}$ & Notes \\
\hline \multicolumn{4}{|c|}{ Fracture Toughness cont'd } \\
\hline ISO $29221: 2014$ & $\begin{array}{l}\text { Determination of mode I plane- } \\
\text { strain crack-arrest toughness }\end{array}$ & No & $\begin{array}{l}\text { Test method for the determination of the plane-strain crack- } \\
\text { arrest fracture toughness, } \mathrm{K}_{1 \mathrm{a}} \text {, of polymeric materials. Side- } \\
\text { grooved, loaded compact tension specimen in tensile } \\
\text { loading. Requires specific wedge loading and grooving of } \\
\text { sample. Not possible in current AM geometries to make test } \\
\text { successful }\end{array}$ \\
\hline ASTM D6068 - 10 & $\begin{array}{l}\text { Standard Test Method for } \\
\text { Determining J-R Curves of } \\
\text { Plastic Materials }\end{array}$ & $\begin{array}{l}\text { Yes with } \\
\text { guidance }\end{array}$ & $\begin{array}{l}\text { Test method to determine the J-integral versus crack growth } \\
\text { resistance curves. Requires optical measurement of crack } \\
\text { growth. Not applicable to opaque samples and potentially } \\
\text { highly anisotropic FDM samples. }\end{array}$ \\
\hline \multicolumn{4}{|l|}{ Impact } \\
\hline ISO $179-1: 2010$ & $\begin{array}{l}\text { Determination of Charpy impact } \\
\text { properties -- Part } 1 \text { : Non- } \\
\text { instrumented impact test }\end{array}$ & $\begin{array}{l}\text { Yes with } \\
\text { guidance }\end{array}$ & See ASTM D6110. Note that test parameters are different \\
\hline ISO $179-2: 1997$ & $\begin{array}{l}\text { Determination of Charpy impact } \\
\text { properties -- Part } 2 \text { : } \\
\text { Instrumented impact test }\end{array}$ & $\begin{array}{l}\text { Yes with } \\
\text { guidance }\end{array}$ & See ASTM D6110. Note that test parameters are different \\
\hline ISO $180: 2000$ & $\begin{array}{l}\text { Determination of Izod impact } \\
\text { strength }\end{array}$ & $\begin{array}{l}\text { Yes with } \\
\text { guidance }\end{array}$ & See ASTM D256. Note that test parameters are different \\
\hline ASTM D256-10 & $\begin{array}{l}\text { Standard test methods for } \\
\text { determining the Izod Pendulum } \\
\text { Impact Resistance of Plastics }\end{array}$ & $\begin{array}{l}\text { Yes with } \\
\text { guidance }\end{array}$ & $\begin{array}{l}\text { Test method to measure the energy to break a specifiied size } \\
\text { specimen under stipulated conditions of mounting, notching } \\
\text { (stress concentration), and pendulum velocity at impact. } \\
\text { Impact geometry and notch differ from D611. }\end{array}$ \\
\hline ASTM D6110-10 & $\begin{array}{l}\text { Standard test method for } \\
\text { determing the Charpy impact } \\
\text { resistance of notched specimens } \\
\text { of plastics }\end{array}$ & $\begin{array}{l}\text { Yes with } \\
\text { guidance }\end{array}$ & $\begin{array}{l}\text { Test method to measure the energy to break a specified size } \\
\text { specimen under stipulated conditions of specimen mounting, } \\
\text { notching (stress concentration), and pendulum velocity at } \\
\text { impact. Note } 3 \text { contains multiple AM relevant process } \\
\text { variables that impact results. }\end{array}$ \\
\hline
\end{tabular}




\begin{tabular}{|c|c|c|c|}
\hline Standard Designation & Standard Name & $\begin{array}{l}\text { Applicable for } \\
\text { AM Testing }\end{array}$ & Notes \\
\hline \multicolumn{4}{|c|}{ Bearing Strength and Open Hole Compression } \\
\hline ASTM D953- 10 & $\begin{array}{l}\text { Standard Test Method for } \\
\text { Bearing Strength of Plastics }\end{array}$ & $\begin{array}{l}\text { Yes with } \\
\text { guidance }\end{array}$ & $\begin{array}{l}\text { The purpose of the test is to determine the bearing } \\
\text { strength of the material and to show the bearing stress } \\
\text { versus the deformation of the hole }\end{array}$ \\
\hline ISO $12815: 2013$ & $\begin{array}{l}\text { Fibre-reinforced plastic } \\
\text { composites -- Determination of } \\
\text { plain-pin bearing strength }\end{array}$ & $\begin{array}{l}\text { Yes with } \\
\text { guidance }\end{array}$ & $\begin{array}{l}\text { Test method that measures ability of composites to carry a } \\
\text { pin through a hole in rectangular sample. The method } \\
\text { described in this International Standard uses the maximum } \\
\text { load to define the plain-pin laminate bearing strength. }\end{array}$ \\
\hline ISO $12817: 2013$ & $\begin{array}{l}\text { Fibre-reinforced plastic } \\
\text { composites -- Determination of } \\
\text { open-hole compression strength }\end{array}$ & No & $\begin{array}{l}\text { This test method determines the open-hole compressive } \\
\text { strength of multidirectional polymer matrix composite } \\
\text { laminates reinforced by high-moduhs fibers. Limited to } \\
\text { continuous- fiber or discontinuous-fiberreinforced } \\
\text { composites in which the laminate is balanced and symmetric } \\
\text { with respect to the test direction. Not likely achieved in AM } \\
\text { processes. }\end{array}$ \\
\hline $\begin{array}{l}\text { ASTM } \\
\text { D5961/D5961 M-13 }\end{array}$ & $\begin{array}{l}\text { Standard test method for } \\
\text { bearing response of polymer } \\
\text { matrix composites }\end{array}$ & $\begin{array}{l}\text { Yes with } \\
\text { guidance }\end{array}$ & $\begin{array}{l}\text { Test method that provides four different configurations to } \\
\text { test the bearing strength of a matrix composite. }\end{array}$ \\
\hline $\begin{array}{l}\text { ASTM } \\
\text { D6484/D6484 M-14 }\end{array}$ & $\begin{array}{l}\text { Standard Test Method for } \\
\text { Open-Hole Compressive } \\
\text { Strength of Polymer Matrix } \\
\text { Composite Laminates }\end{array}$ & No & $\begin{array}{l}\text { This test method determines the open-hole compressive } \\
\text { strength of multidirectional polymer matrix composite } \\
\text { laminates reinforced by high-moduhus fibers. Limited to } \\
\text { continuous-fiber or discontinuous- fiber reinforced } \\
\text { composites in which the laminate is balanced and symmetric } \\
\text { with respect to the test direction. Not likely achieved in AM } \\
\text { processes. }\end{array}$ \\
\hline
\end{tabular}




\section{Polymer Additive Manufacturing at NIST}

An emerging program for polymer AM started in MML in 2014. This program is not a component of the current EL additive manufacturing effort focused on metal AM, but the two laboratory efforts are collaborating to leverage expertise. As mentioned earlier, thermal fusion is a critical component to the strength of AM parts. Maximizing adhesion across the fusion zone requires a balance between diffusion time, residual stress, and maintaining dimensional stability. There are 9 projects addressing challenges in metal and polymer AM. The polymer centric projects are shown below:

\begin{tabular}{|c|c|c|}
\hline FY2015 Projects & Division & Project Leader (s) \\
\hline \multicolumn{3}{|l|}{ Polymer Focus: } \\
\hline $\begin{array}{l}\text { Mechanical Strength of Additive Manufactured } \\
\text { Polymeric Materials }\end{array}$ & 647 & Jason Killgore \\
\hline $\begin{array}{l}\text { Interfaces and Bonding During Additive Manufacturing } \\
\text { of Polymeric Materials }\end{array}$ & 642 & $\begin{array}{l}\text { Kalman Migler; } \\
\text { Kathryn Beers }\end{array}$ \\
\hline $\begin{array}{l}\text { Metrology of Defects and Distortion at Interfaces in } \\
\text { Additive Manufactured Polymeric Materials }\end{array}$ & 642 & $\begin{array}{l}\text { Kalman Migler; } \\
\text { Ronald Jones }\end{array}$ \\
\hline $\begin{array}{l}\text { Metrology of Non-metallic Precursors and Relationships } \\
\text { to Final Product Quality and Performance }\end{array}$ & 643 & $\begin{array}{l}\text { Greg Gillen; Michael } \\
\text { Verkouteran }\end{array}$ \\
\hline $\begin{array}{l}\text { Nanomechanical Property Measurement of Surfaces and } \\
\text { Interfaces for Polymeric and Metal Additive } \\
\text { Manufacturing Materials }\end{array}$ & 643 & Richard Gates \\
\hline
\end{tabular}

For material extrusion AM processes, the focus is on the interfaces of the deposition line and developing molecular level measurements to determine microstructure-processing relationships within this fusion zone. These projects utilize AM process variables such as temperature, speed, and extruded filament size to maximize the width of the diffusion zone between model polymer materials. Polymer structure (chain-length, branching, chemistry) is systematically varied along with process variables. The diffusion zone is directly measured using spectroscopic rheology and neutron reflectivity to determine width, orientation, degree of entanglement, and mechanical properties. The neutron reflectivity studies will be jointly supported through the Additive Manufactured Polymeric Materials project led by Dr. Ronald Jones. Experimental results will be used to generate constitutive models for fusion bond strength and process parameters in collaboration with Georgetown University. The Mechanical Strength of Additive Manufactured Polymeric Materials project is led by Dr. Jason Killgore. Dr. Killgore is utilizing sophisticated elastic and viscoelastic measurements based on scanning probe microscopy and frequency shifts during contact with a material to determine mechanical properties through the fusion line. Future efforts in this project will develop localized adhesion measurements for assessing the strength of the fusion line and potential defects caused by processing parameters. Dr. Richard Gates is utilizing a different set of nanomechanical measurement tools to investigate the mechanical properties of the polymer fusion interfaces. The final project is led by Dr. Greg Gillen and Dr. Michael Verkouteran titled Metrology of Non-metallic Precursors and Relationships to Final Product Quality and Performance. This project investigates the impact of resin properties on the final product properties for material jetting processes. In addition, the impact of photopolymer 
precursor structure and formulation on final properties will be investigated. These efforts are important for developing the measurement science to predict fusion interface strength as a function of processing parameters. The MML effort has a strong focus on structure-property relationships for molecular level performance. This is an important step, but this work would be greatly enhanced with additional work to transition molecular-level knowledge to testing and qualification of AM parts.

There are several areas where NIST laboratories may leverage core expertise to accelerate the measurement science delivered to the AM community. The mechanical properties of any AM part will be a function of the composite and includes the material properties, build geometry (raster angle, filament size, gap, temperature, etc.), voids and defects, and roughness. There are many ASTM and ISO test standards available for AM materials, but a technical basis is required to provide the guidance for testing additive parts to account for anisotropy and develop the models required to predict final mechanical properties. This technical basis will transition the molecular structure-property measurements from MML into standards for testing coupon level samples in the purview of ASTM and ISO standards. Standardizing how materials are built and tested in order to determine mechanical and failure performance for parts in tension, compression, flexure, fatigue, and fracture is key to deploying engineered AM structures with confidence. Further, the development of composite mechanics models for properties of AM parts will inform the MML effort on molecular scale measurements. This engineering effort would close the measurement loop across multiple length scales and provide a route to translate the innovations from molecular scale measurements into the advancement of AM part quality and strength. This is an area where EL and MML may leverage their respective AM programs to improve measurements science, standards, and the AM community. Similar examples of successful collaboration exist in the metal AM programs. A second area of collaboration would be the development of standard reference materials for printing to calibrate the performance of different AM machines. Ultimately, the constitutive equations, standards, and design decisions developed for polymer AM need to be brought into the AM workflow. This is a third area of collaboration between the EL and MML Additive Manufacturing efforts.

\section{Conclusion and Path Forward}

Polymer AM is gaining attention from many press-worthy applications that has helped drive advances in materials and manufacturing equipment. There has been significant investment from private industry and government to foster AM growth. Polymer AM equipment is becoming more accessible to the general public further increasing the possibility for distributed manufacturing of high quality parts and increasing innovation in design. Advances in machine design have led to AM with high performance semi-crystalline polymers and composites, which are creating a demand for better mechanical property measurements. AM process parameters exhibit a non-linear effect on mechanical properties and one of the challenging aspects is maximizing the fusion bond and relating process parameters to polymer structure for thermoplastics, semi-crystalline materials, composites, and thermosets. 
This report helped to outline specific measurement and standards recommendations:

1. Engineers require the ability to compare the rheological, thermal, and size distribution of AM raw materials. In addition, engineers should be able to compare mechanical properties of as received material with material properties of a extruded material. This will alleviate some of the unknowns that users face with printing materials from different lots or printing machines. A classification system should be developed for AM materials so that materials may be classified based on expected mechanical performance. This would allow engineers to identify the physical properties of the polymer such as melt viscosity, molecular weight, and heat capacity, so that material deposition can be optimized.

2. An effort should be made to identify standard reference polymers that could be used to validate AM machine performance.

3. Constitutive equations are required to predict the effect of print parameters on filament geometry and inter-diffusion of polymers.

4. A suite of standard test methods should be developed to support the measurement of material properties for engineering design. The test geometries developed in the standards should be supported by mechanical models to provide an understanding of anisotropy.

5. A better understanding of the durability of AM materials to environmental stresses such as weather, fatigue, creep, and thermal cycling is needed. The presence of residual stress, buried flaws, kissing bonds, and other stress risers will be increase the probability of failure under external stresses.

6. Constitutive equations for polymer structure-property relationships and intelligent printing design to account for intended load paths should be incorporated into the AM workflow to better predict AM final properties.

7. Finally, the AM community of designers and engineers should be supported in the critical aspects of structural properties of polymers and composites to prevent the treatment of soft materials based on past experience with metallic materials.

International standards organizations, namely ASTM and ISO, have developed more than 25 standards each (55 combined) for testing mechanical properties of polymers and composites. A few of the composites standards are intended for materials containing high modulus fibers and are not directly applicable to samples made with current AM processes. On the other hand, studies have shown certain composite standards actually improve test consistency on AM materials compared to geometries for non-composite materials. The majority of existing standards are applicable to testing AM produced parts, but guidance is required to specifically address engineering property measurements from AM processes. This report is intended to provide a brief survey of the landscape for polymer AM and summarize current efforts at NIST to identify technical gaps. The growing application of AM to the biomedical industry will require similar support for standards and material classification. There is an opportunity to leverage the efforts in MML to bridge the length scales to provide measurement science, bulk characterization, and standards to support the growing AM industry. 


\section{Acknowledgements}

The author would like to thank John Slotwinski (The Johns Hopkins University Applied Physics Laboratory), Don Hunston (NIST/EL), Stephanie Watson (NIST/EL), Jon Seppala (NIST/MML), and Kalman Migler (NIST/MML) for their helpful comments, suggestions, and discussions concerning the development of this manuscript. 


\section{References}

[1] ASTM F2792-12a, Standard Terminology for Additive Manufacturing

Technologies, F42.19, Ed. West Conshohocken, PA: ASTM International, 2012.

[Online]. Available: www.astm.org

[2] (Accessed on 11/2014) America Makes. [Online]. Available: https://americamakes.us/

[3] (Accessed on 2/2015) Center for Innovative Materials Processing Through Direct Digital Deposition. [Online]. Available: www.cimp-3d.org

[4] America Makes. (Accessed on 6/2014) America Makes: National Additive Manufacturing Innovation Institute. [Online]. Available: http://manufacturing.gov/$\underline{\text { nnmi_pilot_institute.html }}$

[5] (Accessed on 7/2014) National Center for Defense Manufacturing and Machining. [Online]. Available: ncdmm.org

[6] C. Chua, S. Chou, and T. Wong, "A study of the state-of-the-art rapid prototyping technologies," The International Journal of Advanced Manufacturing Technology, vol. 14, no. 2, pp. 146-152, 1998.

[7] D. K. Leigh, “A comparison of polyamide 11 mechanical properties between laser sintering and traditional molding," in International Solid Freeform Fabrication Proceedings, Bourell, D., Ed. Austin, TX: The University of Texas, 2012, pp. 574-605. [8] C. W. Hull, "EnglishApparatus for production of three-dimensional objects by stereolithography," Grant US 4575330 A, 1986. [Online]. Available: http://www.google.com/patents/US4575330

[9] M. LeGault. (Accessed on 10/2014) The rise of rapid manufacturing. Composites World. [Online]. Available: http://www.compositesworld.com/articles/the-rise-of-rapidmanufacturing

[10] B. Y. Ang, C. K. Chua, and Z. H. Du, "Study of trapped material in rapid prototyping parts," The International Journal of Advanced Manufacturing Technology, vol. 16, no. 2, pp. 120-130, Feb. 2000. [Online]. Available: http://link.springer.com/$10.1007 / \mathrm{s} 001700050017$

[11] T. Wohlers, "Wohlers Report 2012: Additive Manufacturing and 3D Printing State of the Industry," Wohlers Associates, Inc., Report, 2012.

[12] G. Newswire. (Accessed on 7/2014) Global Additive Manufacturing Market (2012-2017): By Application. [Online]. Available: http://www.cnbc.com/id/101083515\# [13] ASD Reports. (Accessed on 8/2014) A new report forecast 3D printing market to grow from 1.95 billion in 2013 to over 10 billion market by 2022 at an estimated CAGR of over $20 \%$ during the same period. [Online]. Available: https://www.asdreports.com/news.asp?pr_id=2545

[14] S. Butler. (2014, August) englishMedical implants and printable body parts to drive 3D printer growth. electronic. theguardian. UK. [Online]. Available: http://www.theguardian.com/business/2014/aug/24/medical-implants-drive-3d-printer-growth 
[15] IDtechex. (2014) 3D Printing Materials 2014-2025: Status, Opportunities, Market Forecasts. [Online]. Available: http://www.idtechex.com/research/reports/3d-printingmaterials-2014-2025-status-opportunities-market-forecasts-000369.asp

[16] ASTM F3112-14, Standard Guide for Evaluating Mechanical Properties of Metal Materials made via Additive Manufacturing Processes, F42.01, Ed. West Conshohocken, PA: ASTM International, 2014. [Online]. Available: www.astm.org

[17] ASTM F3091/F3091M-14, Standard Specification for Powder Bed Fusion of Plastic Materials, F42.05, Ed. West Conshohocken, PA: ASTM International, 2014. [Online]. Available: www.astm.org

[18] ASTM WK 40419, New Test Methods for Performance evaluation of additive manufacturing systems through measurement of a manufactured test piece, F42.01, Ed. West Conshohocken, PA: ASTM International, 2014. [Online]. Available: www.astm.org [19] ISO 17296-3:2014, Additive manufacturing - General principles - Part 3: Main characteristics and corresponding test methods, ISO/TC 261, Ed. Switzerland:

International Standards Organization, 2014. [Online]. Available: http://www.iso.org/iso/catalogue detail.htm?csnumber $=61627$

[20] H. Stahl, “3D Printing - Risks and Opportunities,” Institute for Applied Ecology, Oko-Institut e.V., Darmstadt, Tech. Rep., 2013.

[21] K. Jurrens, Measurement Science Roadmap for Metal-Based Additive Manufacturing, E. Incorporated, Ed. Gaithersburg, MD: National Institute of Standards and Technology, 2013. [Online]. Available: http://www.nist.gov/el/isd/upload/NISTAdd_Mfg_Report_FINAL-2.pdf

[22] J. Slotwinski, “Applicability of Existing Materials Testing Standards for Additive Manufacturing Materials Applicability of Existing Materials Testing Standards for Additive Manufacturing Metal Materials," National Institute of Standards and Technology, Gaithersburg, MD, NISTIR 8005, 2014.

[23] J. Slotwinski, A. Cooke, and S. Moylan, "Mechanical Properties Testing for Metal Parts Made via Additive Manufacturing: A Review of the State of the Art of Mechanical Property Testing," National Institute of Standards and Technology, Gaithersburg, MD, NISTIR 7847, 2012.

[24] S. Bates. (Accessed on 9/2014) 3-D printing and custom manufacturing: from concept to classroom. [Online]. Available: http://nsf.gov/discoveries/disc_summ.jsp?cntn_id=129774

[25] M. Bello. (Accessed on 7/2014) NIST Awards 7.4 Million in Grants for Additive Manufacturing Research. [Online]. Available: http://www.nist.gov/director/3dgrant.cfm [26] (Accessed on 8/2014) Advanced Manufacturing Technology Consortia Program (AMTech). [Online]. Available: http://www.nist.gov/amo/

[27] (Accessed on 7/2014) ORNL, Cincinnati partner to develop commercial largescale additive manufacturing system. [Online]. Available: http://www.ornl.gov/ornl/news/news-releases/2014/ornl-cincinnati-partner-to-develop-commercial-large-scale- 
additive-manufacturing-system-23.http://3dprint.com/14358/3d-printed-car-localmotors/

[28] (Accessed on 8/2014) Additive Manufacturing: Oak Ridge National Laboratory Innovations in Manufacturing. [Online]. Available: http://web.ornl.gov/sci/manufacturing/research/additive/.

[29] B. Krassenstein. (Accessed on 2014) Local Motors Begins Their Six Day Quest to 3D Print the 'Strati' Car Live at IMTS. 3Dprint.com. [Online]. Available: http://3dprint.com/14358/3d-printed-car-local-motors/

[30] E. Krassenstein. (Accessed on 10/2014) World's First 3D Printed Castle is Complete - Andrey Rudenko Now to Print a Full-size House. 3Dprint.com. [Online]. Available: http://3dprint.com/12933/3d-printed-castle-complete/

[31] D. Bourell, M. Leu, and D. Rosen, "Roadmap for Additive Manufacturing: Identifying the Future of Freeform Processing," The University of Texas at Austin, Austin, TX, Tech. Rep., 2009.

[32] (Accessed on 9/2014) Reprap.org. [Online]. Available: http://reprap.org/

[33] (Accessed on 9/2014) Makerspace. [Online]. Available: http://makerspace.com/

[34] T. Moilanen and J. Vladen. (2012) Manufacturing in motion: first survey on 3D printing community. [Online]. Available: http://surveys.peerproduction.net/2012/05/manufacturing-in-motion/

[35] (Accessed on 9/2014) Stratysys. [Online]. Available: www.stratasys.com

[36] (Accessed on 11/2014) 3D Systems. [Online]. Available: www.3dsystems.com

[37] (Accessed on 9/2014) Makerbot. [Online]. Available: www.makerbot.com

[38] G. Gardiner. (Accessed on 9/2014) ORNL demonstrates 3-D printing with carbon fiber. [Online]. Available: http://www.compositesworld.com/blog/post/ornldemonstrates-3-d-printing-with-carbon-fiber

[39] - (Accessed on 10/2014) Two visions of 3-D printing in CFRP. [Online]. Available: http://www.compositesworld.com/blog/post/two-visions-of-3-d-printing-in$\underline{\text { cfrp }}$

[40] S. Black. (Accessed on 8/2014) 3D printing continuous carbon fiber composites? [Online]. Available: http://www.compositesworld.com/articles/3d-printing-continuouscarbon-fiber-composites

[41] H. Bheda, K. Patel, and W. Mondesier. (Accessed on 7/2014) 3d Printing UltraStrong Polymers for End Production. [Online]. Available: www.designnews.com [42] M. Newsome. (Accessed on 7/2014) Arevo Labs announces Carbon Fiber and Nanotube-reinfoced High Performance materials for 3D printing process. [Online]. Available: http://www.solvay.com/en/media/press_releases/20140324-Arevo.html [43] L. Holmes, "ARL-TR-6106: Micro-Composite Fabrication via Field-Aided Laminar Composite ( FALCom ) Processing," Army Research Laboratory, Aberdeen Proving Ground, Tech. Rep. September, 2012. 
[44] ASTM D638 - 10, Standard Test Method for Tensile Properties of Plastics, D20.10, Ed. West Conshohocken, PA: ASTM International, 2011. [Online]. Available:

Www.astm.org

[45] ASTM D790-10, Standard Test Methods for Flexural Properties of Unreinforced and Reinforced Plastics and Electrical Insulating Materials, D20.10, Ed. West Conshohocken, PA: ASTM International, 2011. [Online]. Available: www.astm.org [46] ASTM D256-10, Standard test methods for determining the Izod Pendulum Impact Resistance of Plastics, D20.10, Ed. West Conshohocken, PA: ASTM International, 2010. [Online]. Available: www.astm.org [47] ASTM D5592-94:2010, Standard Guide for Material Properties Needed in Engineering Design Using Plastics, D20.10, Ed. West Conshohocken, PA: ASTM International, 2012, no. Reapproved 2010. [Online]. Available: www.astm.org [48] ASTM D695-10, Standard Test Method for Compressive Properties of Rigid Plastics, D20.10, Ed. West Conshohocken, PA: ASTM International, 2010. [Online]. Available: www.astm.org

[49] ASTM D2990-09, Standard Test Methods for Tensile, Compressive, and Flexural Creep and Creep- Rupture of Plastics, D20.10, Ed. West Conshohocken, PA:

ASTM International, 2009. [Online]. Available: www.astm.org

[50] ASTM D3418-12, Standard Test Method for Transition Temperatures and Enthalpies of Fusion and Crystallization of Polymers by Differential Scanning Calorimetry, D20.30, Ed. West Conshohocken, PA: ASTM International, 2012. [Online]. Available: www.astm.org

[51] ASTM D4473-08, Standard Test Method for Plastics: Dynamic Mechanical Properties: Cure Behavior, D20.10, Ed. West Conshohocken, PA: ASTM International, 2008. [Online]. Available: www.astm.org

[52] ASTM D5045-99(2007)e1, Standard Test Methods for Plane-Strain Fracture Toughness and Strain Energy Release Rate of Plastic Materials, D20.10, Ed. West Conshohocken, PA: ASTM International, 2007. [Online]. Available: www.astm.org [53] "Building Block Approach for Composite Structures," in MIL-HDBK-17-3F: Composite Materials Handbook: Polymer matrix composites materials usage, design, and analysis, 3rd ed., M. S. Corporation, Ed. Fort Washington, PA: Department of Defense, 2002, vol. 3, ch. Chapter 4, pp. 24-29.

[54] J. F. Rodriguez, J. P. Thomas, and J. E. Renaud, "Characterization of the mesostructure of styrene materials," Rapid Prototyping Journal, vol. 6, no. 3, pp. 175$185,2000$.

[55] I. M. Ward and D. W. Hadley, An Introduction to the Mechanical Properties of Solid Polymers, 2 ed. West Sussex: John Wiley and Sons, 1993.

[56] V. Z. Parton, Fracture Mechanics: From Theory to Practice. Philadelphia: Gordon and Breach Science Publishers, 1992. [Online]. Available: http://books.google.com/books/about/Fracture_Mechanics.html?id=nU8N4oh4JQgC\&pgis=1 
[57] S. Ahn, M. Montero, D. Odell, S. Roundy, and P. Wright, "Anisotropic material properties of fused deposition modeling abs," Rapid Prototyping Journal, vol. 8, no. 4, pp. 248-257, 2002. [Online]. Available: http://www.emeraldinsight.com/10.1108/13552540210441166

[58] A. Bellini and G. Selcuk, "Mechanical characterization of parts fabricated using fused deposition modeling," Rapid Prototyping Journal, vol. 9, no. 4, pp. 252-264, 2003. [Online]. Available: http://www.emeraldinsight.com/10.1108/13552540310489631

[59] O. Es-Said, J. Foyos, R. Noorani, M. Mendelson, R. Marloth, and B. Pregger, "Effect of layer orientation on mechanical properties of rapid prototyped samples," Materials and Manufacturing Processes, vol. 15, no. 1, pp. 107-122, 2000.

[60] N. Hill and M. Haghi, "Deposition direction-dependent failure criteria for fused deposition modeling polycarbonate," Rapid Prototyping Journal, vol. 20, no. 3, pp. 221227, Apr. 2014. [Online]. Available: http://www.emeraldinsight.com/doi/abs/10.1108/RPJ-04-2013-0039

[61] B. Huang and S. Singamneni, "Raster angle mechanics in fused deposition modelling," Journal of Composite Materials, vol. 0, no. January, pp. 1-21, Jan. 2014. [Online]. Available: http://jcm.sagepub.com/cgi/doi/10.1177/0021998313519153 [62] C. Lee, S. Kim, H. Kim, and S. Ahn, "Measurement of anisotropic compressive strength of rapid prototyping parts," Journal of Materials Processing Technology, vol. 187-188, pp. 627-630, Jun. 2007. [Online]. Available: http://linkinghub.elsevier.com/retrieve/pii/S0924013606011162

[63] S. H. Masood, K. Mau, and W. Song, "Tensile properties of processed fdm polycarbonate material," Materials Science Forum, vol. 654-656, pp. 2556-2559, Jun. 2010. [Online]. Available: http://www.scientific.net/MSF.654-656.2556

[64] J. Riddick, A. Hall, M. Haile, R. Wahlde, D. Cole, and B. S.J., "Effect of Manufacturing Parameters on Failure in Acrylonitrile-Butadiane-Styrene Fabricated by Fused Deposition Modeling," in AIAA 2012-1571 53rd AIAA/ASME/ASCE/AHS/ASC Structures, Structural Dynamics and Materials Conference. Honolulu, HI: American Institute of Aeronautics and Astronautics, 2012, pp. 1-8.

[65] J. F. Rodriguez, J. P. Thomas, and J. E. Renaud, "Mechanical behavior of acrylonitrile butadiene styrene (abs) fused deposition materials. experimental investigation," Rapid Prototyping Journal, vol. 7, no. 3, pp. 148-158, 2006.

[66] A. K. Sood, R. Ohdar, and S. Mahapatra, "Improving dimensional accuracy of fused deposition modelling processed part using grey taguchi method," Materials \& Design, vol. 30, no. 10, pp. 4243-4252, Dec. 2009. [Online]. Available: http://linkinghub.elsevier.com/retrieve/pii/S0261306909001794

[67] _ - "Parametric appraisal of mechanical property of fused deposition modelling processed parts," Materials \& Design, vol. 31, no. 1, pp. 287-295, Jan. 2010. [Online]. Available: http://linkinghub.elsevier.com/retrieve/pii/S0261306909002945 
[68] B. Tymrak, M. Kreiger, and J. Pearce, "Mechanical properties of components fabricated with open-source 3-d printers under realistic environmental conditions," Materials \& Design, vol. 58, pp. 242-246, Jun. 2014. [Online]. Available: http://linkinghub.elsevier.com/retrieve/pii/S0261306914001538

[69] Q. Sun, G. Rizvi, B. Bellehumeur, and P. Gu, "Effect of processing conditions on the bonding quality of fdm polymer filaments," Rapid Prototyping Journal, vol. 14, no. 2, pp. 72-80, 2008.

[70] A. K. Sood, R. K. Ohdar, and S. S. Mahapatra, "Experimental investigation and empirical modelling of fdm process for compressive strength improvement," Journal of Advanced Research, vol. 3, no. 1, pp. 81-90, Jan. 2012. [Online]. Available: http://linkinghub.elsevier.com/retrieve/pii/S209012321100066X

[71] A. Bagsik, V. Schoppner, and E. Klemp, "Long-term ageing effects on fused deposition modeling parts manufactured with ULTEM 9085," in Solid Freeform Fabrication Symposium Proceedings, Bourell, D., Ed. Austin, TX: The University of Texas, 2012, pp. 556-564.

[72] B. Fulcher and D. K. Leigh, "Effect of segregated first and second melt point on laser sintered part quality and processing," in Solid Freeform Fabrication Symposium Proceedings, Bourell, D., Ed. Austin, TX: The University of Texas, 2012, pp. 556-564.

[73] N. Raghunath and P. M. Pandey, "Improving accuracy through shrinkage modelling by using taguchi method in selective laser sintering," International Journal of Machine Tools \& Manufacture, vol. 47, pp. 985-995, 2007.

[74] M. Schmid, F. Woellecke, and G. Levy, "Long-term Durability of SLS Polymer Components under Automotive Application Environment," in Solid Freeform Fabrication Symposium Proceedings, vol. 12. Austin, TX: The University of Texas, 2012, pp. 277-284.

[75] ASTM F42. (Accessed on 10/2014) Committee F42 on Additive Manufacturing Technologies. ASTM International. [Online]. Available: http://www.astm.org/COMMITTEE/F42.htm

[76] ISO TC261. (Accessed on 7/2014) ISO/TC 261 Additive Manufacturing. [Online]. Available: http://www.iso.org/iso/home/store/catalogue tc/catalogue_tc browse.htm?commid=629086.

[77] ISO 527-1:2012, Plastics - Determination of tensile properties - Part 1: General principles, ISO/TC 61/SC 2, Ed. Switzerland: International Standards Organization, 2012. [Online]. Available: http://www.iso.org/iso/catalogue_detail.htm?csnumber $=56045$ [78] ASTM D3039 / 3039M-14, Standard Test Method for Tensile Properties of Polymer Matrix Composite Materials, D30.04, Ed. West Conshohocken, PA: ASTM International, 2014. [Online]. Available: http://www.astm.org [79] ISO 527-4:1997, Plastics - Determination of tensile properties - Part 4: Test conditions for isotropic and orthotropic fibre-reinforced plastic composites, ISO/TC 61/SC 13, Ed. Switzerland: International Standards Organization, 1997. 
[80] ISO 527-5:2009, Plastics - Determination of tensile properties - Part 5: Test conditions for unidirectional fibre-reinforced plastic composites, ISO/TC 61/SC 13, Ed. Switzerland: International Standards Organization, 2009.

[81] ISO 458-1:1985, Plastics - Determination of stiffness in torsion of flexible materials - Part 1: General method, ISO/TC 61/SC 2, Ed. Switzerland: International Standards Organization, 1985.

[82] ISO 178:2010, Plastics - Determination of flexural properties, ISO/TC 61/SC 2, Ed. Switzerland: International Standards Organization, 2010.

[83] ASTM D6272-10, Standard Test Method for Flexural Properties of Unreinforced and Reinforced Plastics and Electrical Insulating Materials by Four-Point Bending, D20.10, Ed. West Conshohocken, PA: ASTM International, 2011. [Online]. Available: WwW.astm.org

[84] ASTM D7264/D7264M-07, Standard Test Method for Flexural Properties of Polymer Matrix Composite Materials, D30.04, Ed. West Conshohocken, PA: ASTM International, 2011. [Online]. Available: www.astm.org [85] ISO 304:2002, Plastics - Determination of compressive properties, ISO/TC 61/SC 2, Ed. Switzerland: International Standards Organization, 2012.

[86] ASTM D3410 / D3410M - 03(2008), Standard Test Method for Compressive Properties of Polymer Matrix Composite Materials with Unsupported Gage Section by Shear Loading, D30.04, Ed. West Conshohocken, PA: ASTM International, 2008. [Online]. Available: www.astm.org

[87] ISO 14126:1999, Fibre-reinforced plastic composites - Determination of compressive properties in the in-plane direction, ISO/TC 61/SC 13, Ed. Switzerland: International Standards Organization, 1999.

[88] ISO 14129:1997, Fibre-reinforced plastic composites - Determination of the inplane shear stress/shear strain response, including the in-plane shear modulus and strength, by the plus or minus 45 degree tension test method [in plane], ISO/TC 61/SC 13, Ed. Switzerland: International Standards Organization, 2012.

[89] ISO 14130:1997, Fibre-reinforced plastic composites - Determination of apparent interlaminar shear strength by short-beam method, ISO/TC 61/SC 13, Ed. Switzerland: International Standards Organization, 2012.

[90] ASTM D2344/2344M-13, Standard Test Method for Short-Beam Strength of Polymer Matrix Composite Materials, D30.04, Ed. West Conshohocken, PA: ASTM International, 2013. [Online]. Available: www.astm.org [91] ASTM D3518 / D3518M-13, Standard Test Method for In-Plane Shear Response of Polymer Matrix Composite Materials by Tensile Test of a $\pm 45^{\circ}$ Laminate, D30.04, Ed. West Conshohocken, PA: ASTM International, 2013. [Online]. Available: http://www.astm.org 
[92] ASTM D7078/7078M-12, Standard Test Method for Shear Properties of Composite Materials by V-Notched Rail, D30.04, Ed. West Conshohocken, PA: ASTM International, 2012. [Online]. Available: www.astm.org

[93] ASTM D3846-08, Standard Test Method for In-Plane Shear Strength of

Reinforced Plastics, D20.18, Ed. West Conshohocken, PA: ASTM International, 2011. [Online]. Available: www.astm.org

[94] ASTM D4255/4255M-01, Standard Test Method for In-Plane Shear Properties of Polymer Matrix Composite Materials by the Rail Shear Method 1, D30.04, Ed. West Conshohocken, PA: ASTM International, 2007, vol. 01, no. June. [Online]. Available: www.astm.org

[95] ISO 15310:1999, Fibre-Reinforced Plastic Composites - Determination of the inplane shear modulus by the plate twist method, ISO/TC 61/SC 13, Ed. Switzerland: International Standards Organization, 2000.

[96] ASTM D543-14, Standard Practices for Evaluating the Resistance of Plastics to Chemical Reagents, D20.50, Ed. West Conshohocken, PA: ASTM International, 2014. [Online]. Available: http://www.astm.org/Standards/D543.htm

[97] ISO 899-1:2003, Plastics Determination of creep behaviour - Part 1: Tensile creep, ISO/TC 61/SC 2, Ed. Switzerland: International Standards Organization, 2011. [98] ISO 899-2:2003, Plastics Determination of creep behaviour - Part 2: Flexural creep by three-point loading, ISO/TC 61/SC 2, Ed. Switzerland: International Standards Organization, 2013.

[99] ASTM D7774-12, Standard Test Method for Flexural Fatigue Properties of Plastics, D20.10.24, Ed. West Conshohocken, PA: ASTM International, 2013. [Online]. Available: www.astm.org

[100] ASTM D7791-12, Standard Test Method for Uniaxial Fatigue Properties of Plastics, D20.10, Ed. West Conshohocken, PA: ASTM International, 2012. [Online]. Available: www.astm.org

[101] ISO 13003:2003, Fibre-reinforced plastics - Determination of fatigue properties under cyclic loading conditions, ISO/TC 61/SC 13, Ed. Switzerland: International Standards Organization, 2003.

[102] ISO 15850:2014, Plastics Determination of tension-tension fatigue crack propagation - Linear elastic fracture mechanics (LEFM) approach, ISO/TC 61/SC 2, Ed. Switzerland: International Standards Organization, 2014.

[103] ASTM D6115 - 97(2011), Standard Test Method for Mode I Fatigue Delamination Growth Onset of Unidirectional Fiber-Reinforced Polymer Matrix Composites, D30.06, Ed. West Conshohocken, PA: ASTM International, 2011. [Online]. Available: www.astm.org

[104] ISO 15024:2001, Fibre-reinforced plastic composites - Determination of mode I interlaminar fracture toughness, GIC, for unidirectionally reinforced material, ISO/TC 61/SC 13, Ed. Switzerland: International Standards Organization, 2001. 
[105] ASTM D5528-13, Standard Test Method for Mode I Interlaminar Fracture Toughness of Unidirectional Fiber-Reinforced Polymer Matrix Composites, D30.06, Ed. West Conshohocken, PA: ASTM International, 2013. [Online]. Available: www.astm.org [106] ISO 29221:2014, Plastics Determination of mode I plane-strain crack-arrest toughness, ISO/TC 61/SC 2, Ed. Switzerland: International Standards Organization, 2014, vol. 2014.

[107] ISO 13586:2000, Plastics - Determination of fracture toughness (GIC and KIC)Linear elastic fracture mechanics (LEFM) approach, ISO/TC 61/SC 2, Ed. Switzerland: International Standards Organization, 2000.

[108] ISO 13586:2000/Amd 1:2003, Guidelines for the testing of injection-moulded plastics containing discontinuous reinforcing fibres, ISO/TC 61/SC 2, Ed. Switzerland: International Standards Organization, 2003.

[109] ASTM D6068-10, Standard Test Method for Determining J-R Curves of Plastic Materials, D20.10, Ed. West Conshohocken, PA: ASTM International, 2010. [Online]. Available: www.astm.org

[110] ISO 179-1:2010, Plastics - Determination of Charpy impact properties - Part 1: Non-instrumented impact test, ISO/TC 61/SC 2, Ed. Switzerland: International Standards Organization, 2010.

[111] ISO 179-2:1997, Plastics - Determination of Charpy impact properties - Part 2: Instrumented impact test, ISO/TC 61/SC 2, Ed. Switzerland: International Standards Organization, 2012.

[112] ASTM D6110-10, Standard test method for determining the Charpy Impact resistance of notched specimens of plastics, D20.10, Ed. West Conshohocken, PA: ASTM International, 2010. [Online]. Available: www.astm.org

[113] ISO 180:2000, Plastics - Determination of Izod impact strength, ISO/TC 61/SC 2, Ed. Switzerland: International Standards Organization, 2011.

[114] ASTM D953 - 10, Standard Test Method for Bearing Strength of Plastics, D20.10, Ed. West Conshohocken, PA: ASTM International, 2010. [Online]. Available: www.astm.org

[115] ASTM D5961/5961M-13, Standard Test Method for Bearing Response of Polymer Matrix Composite Laminates, D30.05, Ed. West Conshohocken, PA: ASTM International, 2013. [Online]. Available: www.astm.org [116] ASTM D6484/D6484M-14, Standard Test Method for Open-Hole Compressive Strength of Polymer Matrix Composite Laminates, D30.05, Ed. West Conshohocken, PA: ASTM International, 2014. [Online]. Available: www.astm.org [117] ISO 12815:2013, Fibre-reinforced plastic composites - Determination of plainpin bearing strength, ISO/TC 61/SC 13, Ed. Switzerland: International Standards Organization, 2013, vol. 2013. 
[118] ISO 12817:2013, Fibre-reinforced plastic composites - Determination of openhole compression strength, ISO/TC 61/SC 13, Ed. Switzerland: International Standards Organization, 2013, vol. 2013. 